\title{
An Evaluation of the Mellor-Yamada-Janjić Formulation Parameters for the QNSE Scheme in the WRF Model over the Lower Yangtze River Valley
}

\author{
Huiyan $\mathrm{Xu}^{1,2,3}$, Guoqing Zhai ${ }^{1, *}$, Donghai Wang ${ }^{3}$, Hangfeng Shen ${ }^{1,4}$, and Rui Liu ${ }^{1}$ \\ ${ }^{1}$ Department of Earth Science, Zhejiang University, Hangzhou, China \\ ${ }^{2}$ Lishui Meteorological Bureau, Zhejiang Province, China \\ ${ }^{3}$ Chinese Academy of Meteorological Sciences, Beijing, China \\ ${ }^{4}$ Hangzhou Meteorological Bureau, Zhejiang Province, China
}

Received 21 May 2014, revised 27 October 2014, accepted 24 November 2014

\begin{abstract}
Accurate description of boundary layer processes is important for numerical simulations, and some model parameters in the boundary layer schemes play an important role in the model simulations. The Quasi-Normal Scale Elimination (QNSE) scheme in the Weather Research and Forecasting (WRF) model version 3.1.1 reverts into the Mellor-Yamada-Janjić (MYJ) model under unstable and neutral conditions. The parameters $\left(A_{1}, A_{2}, B_{1}, B_{2}, C_{1}\right)$ that affect the turbulent mixing in the MYJ formulation are the proportional coefficients of turbulence length scales and the master turbulence length scale. This study examines the model simulations sensitivity to different MYJ parameters. The simulation results show that MYJ parameters play a significant role in rainfall simulations. The analysis results imply that the parameters may affect the rainfall mainly by changing turbulent mixing and coupling with other physical process, such as cumulus convection processes, and then changing heat, momentum, and moisture transfer. The previous parameters used in the original MYJ formulation are not always the best and none of the parameters are always the best. It may be more appropriate that the parameters should be adopted in their plausible physical bounds depending on the planetary boundary layer (PBL) structures characteristics under specific meteorological and geographical circumstances.
\end{abstract}

Key words: Planetary boundary layer, Heavy rainfall, The Lower Yangtze River, Weather Research and Forecasting model Citation: Xu, H., G. Zhai, D. Wang, H. Shen, and R. Liu, 2015: An evaluation of the Mellor-Yamada-Janjić formulation parameters for the QNSE scheme in the WRF Model over the Lower Yangtze River valley. Terr. Atmos. Ocean. Sci., 26, 283-299, doi: 10.3319/TAO.2014.11.24.01(A)

\section{INTRODUCTION}

China is a vast territory with complicated topography leading to a non-uniform precipitation distribution in both time and space. The annual total precipitation varies from less than $10 \mathrm{~mm}$ in northwest China to more than 2000 mm in southeast China (Wang and Zhang 1989; Zhai et al. 2005). Rainfall is concentrated mainly in summer in most regions of China, with an obvious distinction between the rainy and dry seasons. The major rainy season in eastern China is characterized monsoonal rains. The rain belt moves from south to north as the summer monsoon shifts through a series of dry and rainy phases. Generally speaking, there are six important regional rainy seasons in China from spring to autumn (Xu et al. 1985; Yihui and Zunya 2008). The rain

\footnotetext{
* Corresponding author

E-mail: zhaigq@zju.edu.cn
}

belt stagnates over southern China from middle May to early June, over the Lower Yangtze River region from middle June to early July, over Northern and Northeastern China from middle July to late August. This is called the pre-summer season in South China, Meiyu in the Lower Yangtze River and Huaihe region, rainy season in the Northern and Northeastern China, respectively (Xu et al. 1985). From late August onwards the main rain belt moves back from middle September to early October. The major rain belt stagnates over the Huaihe region, which is called the Autumn Rainy Season in the Huaihe region (Zhai et al. 2005). The Lower Yangtze River region has attracted much attention for its dense inhabitation and frequent heavy rainfall occurrences (Wang et al. 2012). The regions mentioned above are depicted in Fig. 1. However, precipitation is not only related to the synoptic situation, but also closely connected to the planetary boundary layer (Xu and Zhao 2000). 
The planetary boundary layer parameterization is a fundamental issue of meteorological models. Although great efforts have been made by researchers around the world, errors and uncertainties linked to the planetary boundary layer (PBL) parameterizations remain to be one of the crucial sources of inaccurate simulations (Pleim 2007a, b; Hu et al. 2010b; Xu et al. 2013). PBL schemes usually parameterize the heat and momentum fluxes within the PBL, as well as in the free atmosphere (Nielsen-Gammon et al. 2010). These schemes include the parameters or empirical constants used for turbulence parameterization. Different treatments of these parameters or empirical constants may lead to differences in the boundary layer. PBL parameters in some PBL schemes have been evaluated in the Weather Research and Forecasting (WRF) model framework. For example, a study by $\mathrm{Hu}$ et al. (2010b) concluded that the vertical eddy diffusivity in the Asymmetrical Convective Model version 2 (ACM2) PBL scheme varies considerably when the index number $\mathrm{p}$ in the vertical eddy diffusivity formulation varies between 1 - 3 (Hu et al. 2010b). It governs the vertical mixing strength. Another study by John W. Nielsen-Gammon tested the sensitivities of model simulations to the ACM2 parameters. His study shows that ACM2 parameters have a great effect on the vertical profiles of temperature, water vapor mixing ratio and wind speed (Nielsen-Gammon et al. 2010). The above studies identified important parameters in the ACM2 scheme. Significant parameters in other PBL schemes should also be identified.

We compared seven PBL schemes in the WRF model framework in the rainfall simulation in the Lower Yangtze River Reaches (Xu et al. 2013). The seven PBL schemes include the Quasi-Normal Scale Elimination (QNSE) PBL scheme, the Mellor-Yamada-Janjić (MYJ) PBL scheme, Mellor-Yamada-Nakanishi and Niino Level-2.5 (MYNN2.5) PBL scheme, Mellor-Yamada-Nakanishi and Niino Level-3 (MYNN3) PBL scheme, Yonsei University (YSU) PBL scheme, ACM2 PBL scheme, Bougeault-Lacarrére (Boulac) PBL scheme. Results show that the QNSE scheme performs well in the simulation of rainfall in the Lower Yangtze River Reaches. The reason for the favorable QNSE scheme performance may be that improved parameterization of the stable part could also improve simulation of the unstable part (Xu et al. 2013). QNSE PBL scheme in the WRF model consists of two parts, one is the MYJ scheme designed for unstable and neutral situations and the other is the original QNSE model designed for stably stratified flows. To avoid confusion, it may be more suitable to be entitled QNSE-MYJ (QMYJ) PBL scheme instead of QNSE PBL scheme in the WRF model. Hereafter, QNSE PBL scheme in the WRF model means QMYJ PBL scheme. The mixing coefficients $\left(A_{1}, A_{2}\right.$, $B_{1}, B_{2}, C_{1}$ ) are only used in the MYJ scheme (hereafter MYJ parameters), and they affect turbulent mixing. The impacts of turbulence length scale coefficients $\left(A_{1}, A_{2}, B_{1}, B_{2}, C_{1}\right)$ on simulations within the QMYJ scheme in the WRF model may be evaluated for their importance. The techniques and methods used to revise vertical mixing coefficients remain general (Janjić 2001). Using the techniques and methods of the previous study (Janjić 2001), we can establish one to one correspondence between the model parameters and the Prandtl number (Prt). The parameter choice will therefore be made by the Prt (Table 1). The original Prt value is assigned as 0.8. The M-Y model (Mellor and Yamada 1974) has been reported to underestimate the depth of the mixed layer (Sun and Ogura 1980). However, certain progress has been made concerning the growth of the convective boundary layer (CBL) by revising the empirical constants and the new values assigned by taking Prt to 1.0 (Janjić 2001). It is concluded that the MYJ model performance is related to the parameters (Janjić 1994), but the impact of the MYJ formulation on the QMYJ scheme in the WRF model remains unknown. This study investigates the effects of those MYJ parameters in the QMYJ scheme in the WRFV3.1.1 model.

The objective of our research program is to revise the MYJ parameters $\left(A_{1}, A_{2}, B_{1}, B_{2}, C_{1}\right)$ in the QMYJ scheme. As a necessary first step in the program, this study evaluates the sensitivities of the WRF simulations to those MYJ parameters in the QMYJ PBL scheme over the Lower Yangtze River regions. To achieve this goal MYJ parameters are assigned one of six value sets (Table 1) for each case. Comparisons between the wind speed, potential temperature, water vapor mixing ratio, PBL height, 24-hour accumulated rainfalls from the measurements and simulations are performed. Sensitivity results are also analyzed using statistical methods. The sensitivity analysis enables us to understand the sources and characteristics of the model error, facilitating PBL scheme improvement. The overall methods of this study remain general.

The paper is organized in the following order. In section 2 the original QNSE model is described and the parameters to be tested in the MYJ formulation of the QMYJ scheme are reviewed in detail. Section 3 gives a description of the model setup. Section 4 examines the model sensitivity to each set of parameters by evaluating PBL variables, structures, heights, and finally verifying the rainfall fields. A brief summary is provided in section 5 as a conclusion.

\section{A DESCRIPTION OF QNSE PARAMETERIZATION AND MYJ PARAMETERS}

The QNSE PBL scheme is one of the TKE closure schemes (Skamarock et al. 2008). The QNSE model distinguishes between the horizontal transportation processes and the vertical transportation processes. Using a renormalization group theory around a Reynolds number of unity, it considers the joint effect of turbulence and waves in the presence of turbulence with stable and weakly unstable stratification (Sukoriansky 2008). The QNSE model gives a variety of significant stably stratified flow features, for example, the reliance of vertical turbulent Prt on Froude and Richardson 
numbers, anisotropization of air flow, and the reduction of vertical diffusivity in the condition of strong stratification (Sukoriansky et al. 2005; Sukoriansky 2008). Details of the QNSE PBL can be referred to in the study of Sukoriansky (2008) and Galperin et al. (2010). The QNSE scheme in the WRFV3.1.1 model applies MYJ scheme (Sukoriansky 2008) in unstable situations, thus the QNSE is renamed QMYJ scheme as previously declared in the introduction. The MYJ parameters are turbulence length scale coefficients in the
MYJ parameterization of the QMYJ scheme (Mellor and Yamada 1982). The MYJ parameters that control turbulent mixing are monotonic functions of the Prt and their effects on the simulations can be evaluated through trial and error (Janjić 2001). Their values can then be obtained according to the Prt (Table 1). Here, we first discuss the formulations and variables that are important to understand the physical significance of the MYJ parameters.

The second-moment turbulent closure model (Moeng
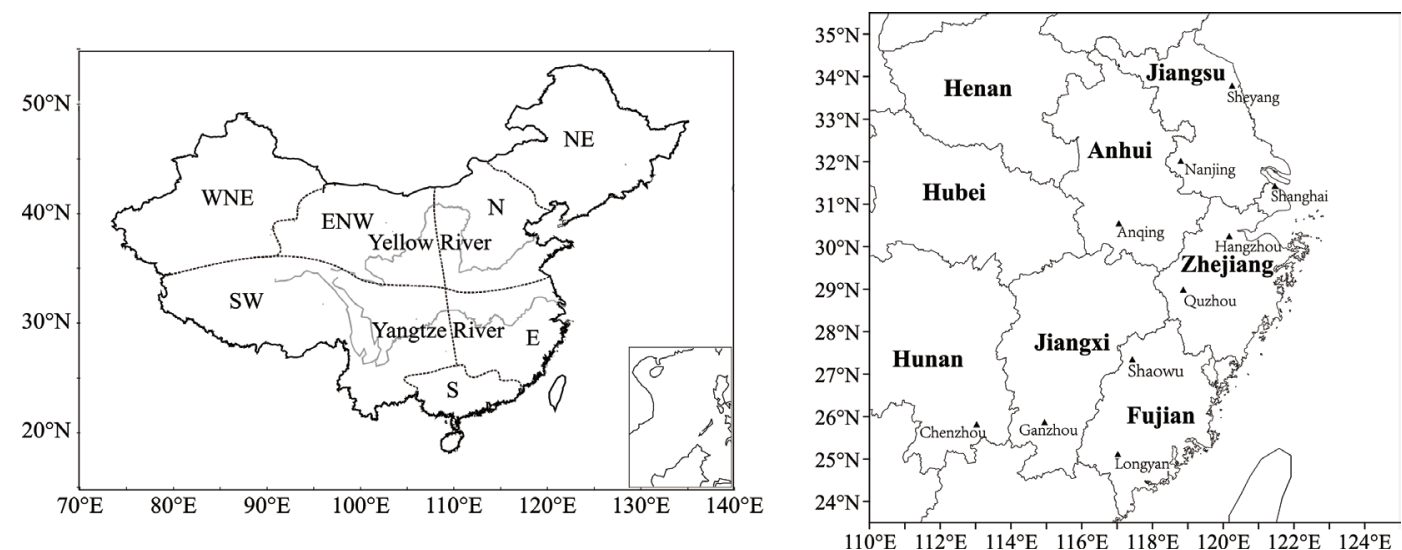

Fig. 1. Map of China with geographic regions (left) and administrative divisions (right), $\mathbf{\Delta}$ denotes the city mentioned in the paper. North China consists of Northeast, north, eastern northwest, and western northwest, marked by NE, N, ENW, and WNE respectively. Southwest, East, and South are marked by SW, E, and S respectively, and together they constitute South China.

Table 1. A summary of different QMYJ PBL scheme numerical experiments.

\begin{tabular}{|c|c|c|}
\hline Experiments & PBL scheme & $\left(A_{1}, A_{2}, B_{1}, B_{2}, C_{1}\right)$ \\
\hline QMYJ 0.7 & $\begin{array}{l}\text { MYJ formulation with } \\
\text { Prt }=0.7\end{array}$ & $\begin{array}{l}A_{1}=1.12673953 \\
A_{2}=0.78576836 \\
B_{1}=20.28131156 \\
B_{2}=12.33983354 \\
C_{1}=0.113745091\end{array}$ \\
\hline QMYJ 0.8 & $\begin{array}{l}\text { MYJ formulation with } \\
\text { Prt }=0.8\end{array}$ & $\begin{array}{l}A_{1}=0.92 \\
A_{2}=16.6 \\
B_{1}=0.74 \\
B_{2}=10.1 \\
C_{1}=0.08\end{array}$ \\
\hline QMYJ 0.9 & $\begin{array}{l}\text { MYJ formulation with } \\
\text { Prt }=0.9\end{array}$ & $\begin{array}{l}A_{1}=0.77287067 \\
A_{2}=0.70525886 \\
B_{1}=13.9116721 \\
B_{2}=8.02996869 \\
C_{1}=0.042895308\end{array}$ \\
\hline QMYJ & MYJ formulation & Default values of the original QNSE PBL scheme in the WRFV3.1.1 model \\
\hline QMYJ 1.1 & $\begin{array}{l}\text { MYJ formulation with } \\
\mathrm{Prt}=1.1\end{array}$ & $\begin{array}{l}A_{1}=0.5719809488 \\
A_{2}=0.6268263108 \\
B_{1}=10.2956570800 \\
B_{2}=6.26422478898 \\
C_{1}=0.04566119176\end{array}$ \\
\hline QMYJ 1.2 & $\begin{array}{l}\text { MYJ formulation with } \\
\mathrm{Prt}=1.2\end{array}$ & $\begin{array}{l}A_{1}=0.501994226 \\
A_{2}=0.6001405018 \\
B_{1}=9.03589608219 \\
B_{2}=5.49774373687 \\
C_{1}=0.096658117954\end{array}$ \\
\hline
\end{tabular}


and Wyngaard 1989) hypothesizes that length scales are proportional to the master length scale (Mellor and Yamada 1982), and their equation can be expressed as

$\left(l_{1}, \Lambda_{1}, l_{2}, \Lambda_{2}\right)=\left(A_{1}, B_{1}, A_{2}, B_{2}\right) \cdot l$

where $\left(l_{1}, \Lambda_{1}, l_{2}, \Lambda_{2}\right)$ are length scales, $l$ is the master turbulent length scale, $\left(l_{1}, l_{2}, \Lambda_{1}, \Lambda_{2}\right)$ and $C_{1}$ are related to the momentum flux, heat flux, the dissipation of turbulent flux and the potential temperature variance $\left\langle\theta^{2}\right\rangle$, respectively. The vertical flux of momentum in the x direction, and $\left(A_{1}, A_{2}, B_{1}\right.$, $B_{2}, C_{1}$ ) are closure constants which can be determined from data. Overall, they are related to turbulent mixing. Length scales determine the capability of turbulent mixing (Stull 1991). Turbulent transportation has some relationship with atmospheric movement of convergence or divergence $\mathrm{Hu}$ and Zuo 2003), and it is meaningful to get reasonable chosen set of these constants.

In the MYJ model (Mellor and Yamada 1982; Janjić 2001), the basic equations for the ensemble mean velocity $(U, V)$, pressure $(P)$ and potential temperature $\Theta$ have been introduced. The turbulence field is described using a differential equation for turbulent kinetic energy (TKE) per unit mass $\left(q^{2} / 2\right)$ and algebraic equations for the second momentums. More details can be found in Mellor and Yamada (1982). By defining the non-dimensional variables: wind shear $\left(G_{M}\right)$, vertical gradient of potential temperature $\left(G_{H}\right)$, diffusion coefficients for momentum $\left(S_{M}\right)$ and heat $\left(S_{H}\right)$, then the equations for turbulent variances and covariances after considerable algebra reduce to

$$
\begin{aligned}
& S_{M}\left[6 A_{1} A_{2} G_{M}\right]+S_{H}\left[1-3 A_{2} B_{2} G_{H}-12 A_{1} A_{2} G_{H}\right]=A_{2} \\
& S_{M}\left[1+6 A_{1}^{2} G_{M}-9 A_{1} A_{2} G_{M}\right]- \\
& S_{H}\left[12 A_{1}^{2} G_{H}+9 A_{1} A_{2} G_{H}\right]=A_{1}\left(1-3 C_{1}\right)
\end{aligned}
$$

From the turbulent energy shear production equations $\left(P_{s}\right)$, buoyant production $\left(P_{b}\right)$ and model dissipation $(\varepsilon)$ show that

$$
\frac{P_{s}+P_{b}}{\varepsilon}=B_{1}\left(S_{M} G_{M}+S_{H} G_{H}\right)
$$

It is easy to solve $S_{M}$ and $S_{H}$ from Eqs. (2) and (3), by virtue of the production-dissipation balance. We can then get $S_{M}$ and $S_{H}$ as functions of flux Richardson number $\left(R_{f}\right)$. The resulting relations are:

$S_{H}=3 A_{2} \frac{\gamma_{1}-\left(\gamma_{1}+\gamma_{2}\right) R_{f}}{1-R_{f}}$

$S_{M}=\frac{A_{2}}{A_{1}} \frac{B_{1}\left(\gamma_{1}-C_{1}\right)-\left[B_{1}\left(\gamma_{1}-C_{1}\right)+6\left(A_{1}+3 A_{2}\right)\right] R_{f}}{B_{1} \gamma_{1}-\left[B_{1}\left(\gamma_{1}+\gamma_{21}\right)-3 A_{1}\right] R_{f}} S_{H}$ where ${ }_{G_{H}} \gamma_{1} \frac{1}{S_{H}}-\frac{2 A_{1}}{B_{1}}, \quad \gamma_{2}=\frac{B_{2}}{B_{1}}+\frac{6 A_{1}}{B_{1}}, \quad R_{f}=-\frac{P_{b}}{P_{s}}$, $R_{i}=-\frac{G_{H}}{G_{M}}=\frac{S_{H}}{S_{M}} R_{f}$.

As the methods used in the MYJ model (Janjić 2001), the equations for the parameters can be obtained as follows:

$A_{1}=\frac{1}{2}\left(\frac{R_{B} F_{B}^{2}}{P_{r t}}\right)^{\frac{3}{2}}\left(\frac{1}{3}-\gamma_{1}\right)$

$A_{2}=\frac{1}{3 \gamma_{1}}\left(\frac{1}{P_{r t} R_{B} F_{B}^{2}}\right)^{\frac{1}{2}}$

$B_{1}=\left(\frac{R_{B} F_{B}^{2}}{P_{r t}}\right)^{\frac{3}{2}}$

$B_{2}=\left(\frac{R_{B} F_{B}{ }^{6}}{P_{r t}{ }^{3}}\right)^{\frac{1}{2}}$

$C_{1}=\gamma_{1}-\frac{2}{1-3 \gamma_{1}} \frac{\operatorname{Prt}^{2}}{R_{B}^{2} F_{B}^{4}}$

where $F_{B}^{2}=\left[u^{2}<\theta^{2}>/ H^{2}\right], R_{B}=\frac{B_{1}}{B_{2}}, \theta$ is the turbulent fluctuation temperature and they are constants as supposed in the determination of the constants in the MYJ model (Janjić 2001). By virtue of Eqs. (7a) - (7e), it is easy to get a set of parameters by taking a Prt. The Prt can be then defined as

$\operatorname{Prt}^{-1}=\frac{K_{H}}{K_{M}}=\frac{\partial V / \partial z}{\partial \Theta / \partial z} \cdot \frac{\langle\theta w\rangle}{\langle\nu w>}$

Where $v$ and $w$ are the turbulent fluctuation velocity, $\Theta$ is the ensemble mean temperature and $V$ is the ensemble mean velocity.

The Prt may be seen to be a ratio reflecting the ratio of the rate that viscous forces penetrate the material to the rate that thermal energy penetrates the material (Schlichting 1979). It varies across a boundary layer. However, in which manner it changes has not been determined yet (Schlichting 1979). It seems that Prt has a value at the wall and increases to a value of 0.5 away from the wall according to Schlichting (1979). However near the wall, the Prt is between 0.74 - 0.92 (Kestin and Richardson 1961). Gowen and Smith (1968) inferred that the Prt should be between $0.8-1.0$ for smooth pipes and between $1.0-1.2$ in rough pipes with a Reynolds number equal to 20000 . In practice a constant value of 1 is frequently often assumed (Schlichting 1979). The physical range of Prt is small, perhaps $1.39^{-1}-1.0$ (0.72 - 1.0) according to Foken (2006) and Nielsen-Gammon et al. (2010). Summarizing the above researches, the maximum range for Prt is $0.7-1.2$. Noting that the value of 1.0 for Prt is the default value of the previous QMYJ PBL scheme used in the WRFV3.1.1 (refer to source code) and 0.8 is the 
value determined from data in the Mellor-Yamada Level 2.5 model (Mellor and Yamada 1982). We choose the value of $0.7,0.8,0.9,1.0,1.1$, and 1.2 for Prt, respectively. According to Eqs. (7a) - (7e), we can obtain the corresponding values of the MYJ parameters (Table 1) to conduct simulation experiments for the purpose of investigating those MYJ parameters for the Lower Yangtze River rainfall simulations.

By virtue of Eqs. (5) - (6), Fig. 2 shows the variation in $S_{M}$ and $S_{H}$ with $R_{f}$ for the super equilibrium approximation. It compares six different cases with different values for the parameters $\left(A_{1}, A_{2}, B_{1}, B_{2}, C_{1}\right)$ by taking the Prt value from 0.7 - 1.2. Figure 2 shows the different functions of $S_{M}$ and $S_{H}$ when different MYJ parameters are applied. Both $S_{M}$ and $S_{H}$ change greatly with different parameters in unstable stratification. As the parameters vary with Prt decreasing from $1.2-0.7$, the turbulent energy buoyant and shear production are increasingly enhanced. Buoyancy fluxes and momentum fluxes develop with decreasing Prt in unstable conditions and the thermal and dynamic motions are sensitive to the parameters in unstable conditions. However, in stable stratification, thermal and dynamic effects vary little when different parameters are applied.

\section{EXPERIMENTAL DESIGNS}

Three model domains with two-way nesting are used (Fig. 3) with grid spacings of 45, 15, $5 \mathrm{~km}$. All model domains consist of 28 full- $\sigma$ vertical layers and the model top is set at $50 \mathrm{hPa}$. The lowest model sigma levels are at 1.000 , $0.990,0.978,0.964,0.946,0.922,0.894,0.860$, and 0.817 . Most of the Lower Yangtze River areas are covered by the $5-\mathrm{km}$ domain. The physical schemes used in all model domains include Rapid Radioactive Transfer Model (RRTM), Long Wave Radiation (Mlawer et al. 1997), Dudhia shortwave radiation (Dudhia 1989), WRF single-moment 5-class (WSM5) microphysics (Hong et al. 2004), 5-layer thermal diffusion land surface scheme (Dudhia 1996) and New Grell (Gs) cumulus scheme (Grell and Dévényi 2002). Six 36-hour forecasts over the three cases, which were initiated at 0000 UTC 23 July 2009, 0000 UTC 3 June 2011, and 1200 UTC 13 June 2011, respectively. Hereafter, the three cases are simply denoted as 20090723, 20110604, and 20110614. In each case the MYJ parameters are assigned one of the six sets of values in Table 1. The National Centers for Environmental Prediction (NCEP) global forecast system (GFS) six-hourly data are used as the initial conditions and boundary conditions for the model runs. The first 12-hour of each simulation are treated as spin-up and the remaining 24-hour are used for analysis. Data for model validation includes surface observations data at National Meteorological Administration (NMA) sites, radiosonde data in national principal (RS) stations and wind profiler (WP) data in Shanghai

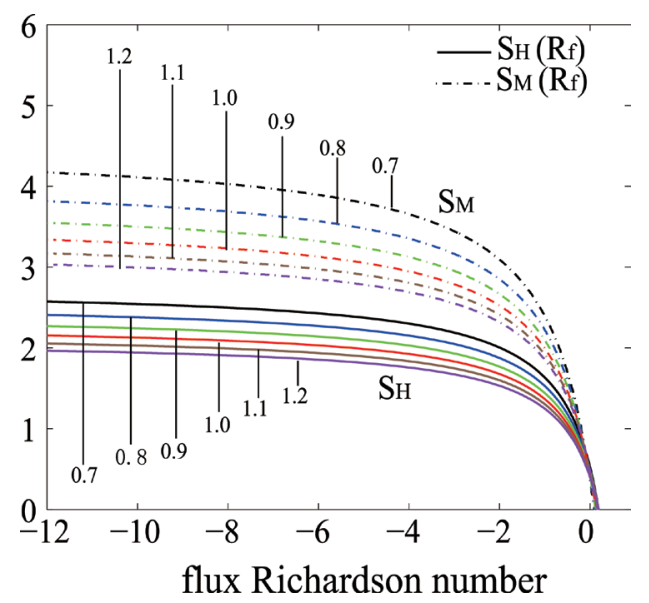

Fig. 2. The stability functions $S_{M}$ (dashed lines) and $S_{H}$ (solid lines) as functions of flux Richardson number corresponding to the condition $\frac{P_{s}+P_{b}}{\varepsilon}=1$. The purple, grey, red, green, blue, and black lines are cases of specific parameters $\left(A_{1}, A_{2}, B_{1}, B_{2}, C_{1}\right)$ by taking the value of $1.2,1.1,1.0,0.9,0.8,0.7$ for Prt, respectively.
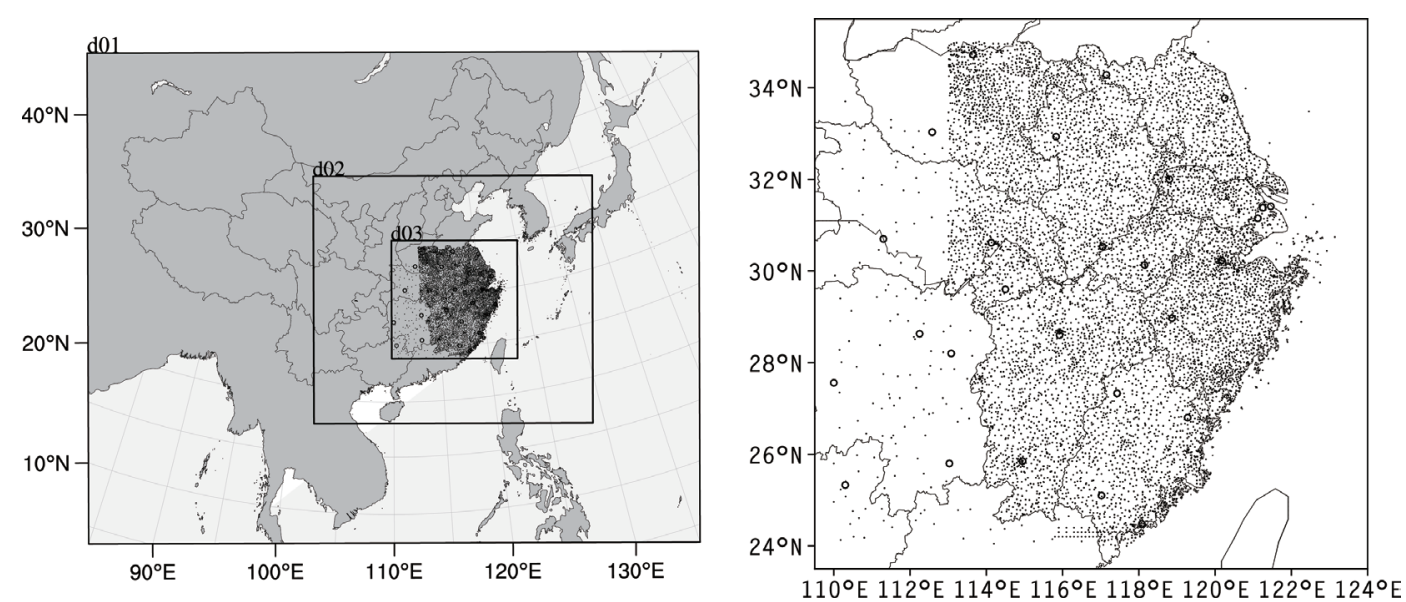

Fig. 3. Map of model domains (left) in the Lambert projection and locations (right) of NMA (dots) and RS - WP (hollow circles) in the latitudelongitude projection. 
stations. The locations of the NMA and RS - WP sites are shown in Fig. 3. Analysis and verification will concentrate on the $15-\mathrm{km}$ domain which contains information from the 5 -km domain through two-way nesting.

The precipitation simulations were interpolated on the surface observation sites in this study. The surface observation site distribution for the three Lower Yangtze River cases $(20090723,20110604$, and 20110614) covers the main rainfall areas, with a grand total sample of more than 3000 sites (Fig. 3). Threat score and hit rate are used to verify the quantitative precipitation forecasts provided by WRFV3.1.1 model. Four thresholds are given for quantitative precipitation verification: they are $0.1,50,100,150 \mathrm{~mm}$, representing different grades of rainfall strength. As the maximum 24-hour accumulated rainfall for case 20110614 is less than $200 \mathrm{~mm}$. Verification is performed for the $0.1,50,100$, and $150 \mathrm{~mm}$ thresholds, and applied to the other two cases. The accuracy (percent correct) is written as:

$\mathrm{Eh}=\frac{N_{a}+N_{d}}{N_{a}+N_{b}+N_{c}+N_{d}}$

Here, $N_{a}, N_{b}, N_{c}$, and $N_{d}$ are defined as follows:

$N_{a}$ : Number of stations where observed and forecasted precipitation are above a threshold (hits).

$N_{b}$ : Number of stations where forecasted precipitations are above a threshold (hits) while the observed are below (false alarms).

$N_{c}$ : Number of stations where observed precipitation are above a threshold (hits) while the forecasted are below (misses).

$N_{d}$ : Number of stations where forecasted and observed precipitation are below threshold (correct negatives).

The accuracy is the fraction of the correct forecasts. Its value is 1 for a correct forecast and it varies from $0-1$, and the perfect score is 1 . It is simple and intuitive. It is greatly impacted by the category, usually no-rain events in the case of rare weather and the percentage correct is dominated by the no-rain frequency (Stanski et al. 1989).

Threat score (Ts) (Critical Success Index) is written as:

$\mathrm{Ts}=\frac{N_{a}}{N_{a}+N_{b}+N_{c}}$

The threat score is the fraction of the hits. Ts measures comparable accuracy, the range is from $0-1$, and the perfect score is 1 . It is obvious that Ts is only connected with forecasts that count (Stanski et al. 1989).

Mean absolute bias is used to verify the wind simulations. Mean absolute bias in the PBL can be written as:

$\sum_{i=1}^{n}\left|\vec{V}_{i}-\vec{V}_{o i}\right| / n$ where $\vec{V}_{i}$ and $\vec{V}_{o i}$ are simulated and observed wind speeds in the specific level and $n$ is the number of levels. The smaller the mean absolute bias is, the closer the model-predicted wind speeds to the observations.

PBL height direct measurement is not available in the Lower Yangtze River regions. It can be diagnosed from potential temperature and wind speed vertical profiles (Liu and Liang 2010). The radiosonde data is reported only for the standard levels and significant levels. The potential temperature is calculated using temperature and pressure from radiosonde data. The surface level is regarded as the first level. The data is first linearly interpolated every $5-\mathrm{hPa}$. The PBL height is diagnosed by first identifying the regime by examining the near-surface thermal gradient between the fifth and second levels:

$\theta_{5}-\theta_{2} \begin{cases}<-\delta & \rightarrow \text { an unstable regime } \\ >+\delta & \rightarrow \text { a stable regime } \\ \text { else } \rightarrow \text { a neutral regime }\end{cases}$

where $\theta$ is the potential temperature and its subscript number denotes the data level index assuming surface air at $l=1$. $\delta_{s}$ is the $\theta$ increment for the minimum strength of the stable layer above the CBL top or below the stable boundary layer (SBL) top. The value of $\delta_{s}$ is $1.0 \mathrm{~K}$.

For the unstable regime, scan upward to find the lowest level that meets the condition:

$\theta_{k}-\theta_{1} \geq \delta_{u}$

where $\delta_{u}$ is the $\theta$ increment for the minimum unstable layer strength. This first-guess level $k$ is then corrected using another upward scan to search for the first occurrence of

$\dot{\theta}_{k} \equiv \frac{\partial \theta_{k}}{\partial z} \geq \dot{\theta}_{r}$

where $\dot{\theta}$ is the $\theta$ vertical gradient per height $z$ and $\dot{\theta}_{r}$ is the minimum overlaying inversion layer strength. $\dot{\theta}_{r}$ is considered as overshooting the rising parcel threshold and thus defines the scope of the entrainment zone for the CBL. Here $\delta_{s}, \delta_{u}$, and $\dot{\theta}_{r}$ are $1.0,0.5$, and $4.0 \mathrm{~K}$ respectively. The same procedure is adopted to determine the neutral regime PBL height.

For a stable regime the PBL height is defined at either the top of the bulk stable layer starting from the grounding in case of forced buoyancy or at the lower level jet (LLJ) nose if present in the case of driven shear. In the case where the SBL turbulence is forced mainly by buoyancy, we scan upward to find the lowest level at which $\dot{\theta}_{k}$ reaches a minimum and then determine the PBL height at that level if either of the following conditions are met: 
$\left\{\begin{array}{l}\dot{\theta}_{k}-\dot{\theta}_{k-1}<-\dot{\delta} \\ \dot{\theta}_{k+1}<\dot{\theta}_{r}, \dot{\theta}_{k+2}<\dot{\theta}_{r}\end{array}\right.$

Otherwise, the LLJ nose is identified at the level where the wind speed reaches a maximum that is at least $2 \mathrm{~m} \mathrm{~s}^{-1}$ stronger than the layers above and below while decreasing monotonically toward the surface (Bonner 1968; Stull 1988). For the case that the stable layer is deep and LLJ is strong, the PBL height is defined at the lower height of the two diagnosed from the thermal height of the two diagnosed from the thermal and dynamic profiles. During the PBL heights diagnosis of those sites in section 4.3, in the case of a stable regime, the above conditions Eq. (15) are met and we need not appeal to the wind speeds.

\section{MODEL RESULTS FROM DIFFERENT EXPERIMENTS}

\subsection{PBL Variables}

To understand the PBL physical processes we investigate the PBL variables sensitivity to the MYJ parameters. The hourly wind speeds from measurements observed with WP in Shanghai stations are used to evaluate the modelpredicted wind speeds in Table 2 .

Figure 4 shows the time evolution of the standard PBL variables deviation (wind speed, potential temperature, water vapor mixing ratio) and TKE below $4000 \mathrm{~m}$. The PBL height from QMYJ is plotted for analysis. For case 20090723, from 0000 UTC 24 July to 1100 UTC 24 July 2009, both PBL variables and TKE show obvious sensitivities to the parameters

Table 2. 24-hour mean absolute bias of wind speed (unit: $\mathrm{m} \mathrm{s}^{-1}$ ) between simulations with QMYJ0.7, QMYJ0.8, QMYJ0.9, QMYJ, QMYJ1.1, QMYJ1.2 and measurements for the three cases.

\begin{tabular}{ccccccc}
\hline \multirow{2}{*}{ case } & \multicolumn{7}{c}{ QMYJ PBL schemes } \\
\cline { 2 - 7 } & QMYJ 0.7 & QMYJ 0.8 & QMYJ 0.9 & QMYJ & QMYJ 1.1 & QMYJ 1.2 \\
\hline 20090723 & 2.732 & 2.554 & $\mathbf{2 . 4 3 1}$ & 2.624 & 2.672 & 2.733 \\
20110604 & $\mathbf{3 . 1 5 4}$ & 3.229 & 3.246 & $\mathbf{3 . 1 5 4}$ & 3.183 & 3.193 \\
20110614 & $\mathbf{5 . 1 0 0}$ & $\mathbf{5 . 1 1 3}$ & 5.254 & 5.229 & 5.263 & 5.354 \\
\hline average & 3.662 & $\mathbf{3 . 6 3 2}$ & 3.644 & 3.669 & 3.706 & 3.760 \\
\hline
\end{tabular}

(a1)

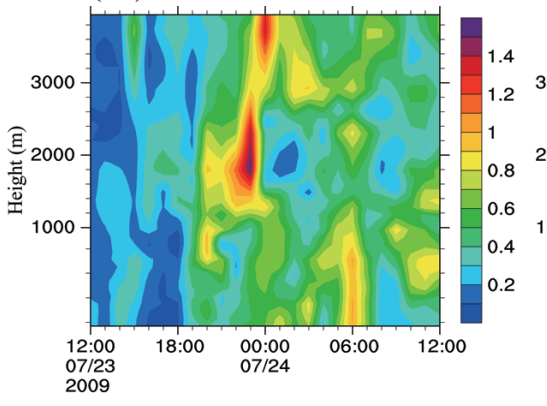

(b) (a2)

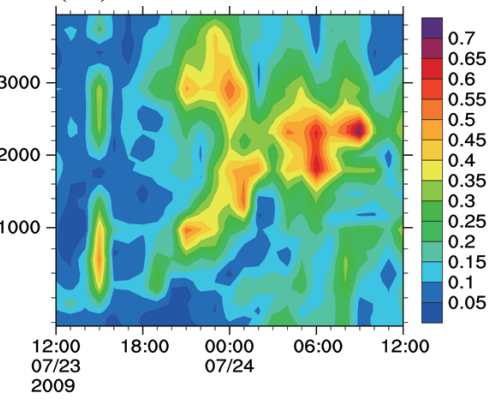

(a3)

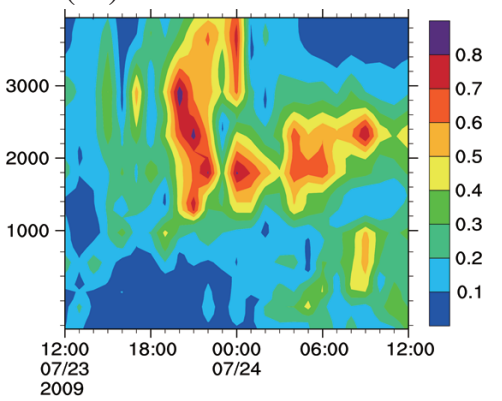

(c)
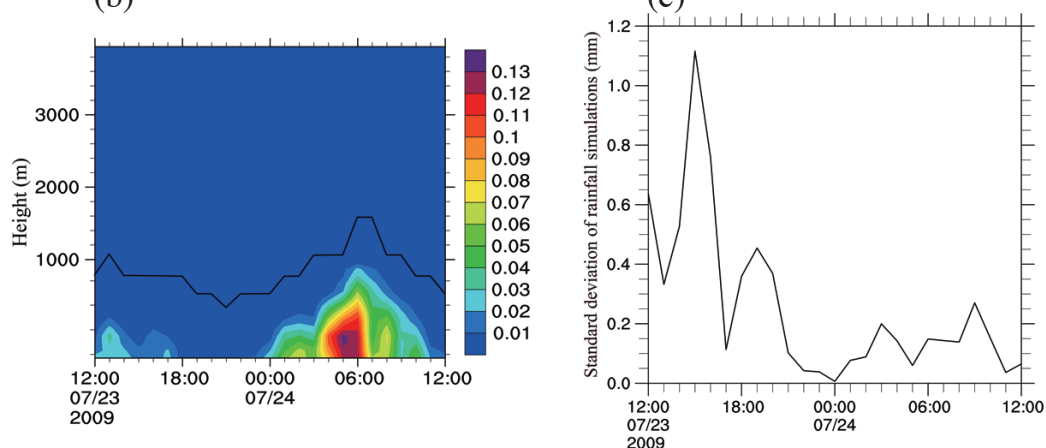

Fig. 4. Standard deviations of wind speed (a1 - a3, unit: $\left.\mathrm{m} \mathrm{s}^{-1}\right)$, potential temperature $\left(\mathrm{d} 1-\mathrm{d} 3\right.$, unit: $\left.{ }^{\circ} \mathrm{C}\right)$, water vapor mixing ratio $\left(\mathrm{g} 1-\mathrm{g} 3\right.$, unit: $\left.\mathrm{g} \mathrm{kg}{ }^{-1}\right)$, turbulent kinetic energy (b, e, h, unit: $\left.\mathrm{m}^{2} \mathrm{~s}^{-2}\right)$ and 1-hour rainfall $(\mathrm{c}, \mathrm{f}, \mathrm{i})$ with respect to parameters for the three cases: $(\mathrm{a} 1$ - $\mathrm{a} 3, \mathrm{~b}, \mathrm{c})$ for case 20090723 at Jianding of Shanghai; (d1 - d3, e, f) for case 20110604 at Qingpu of Shanghai; (g1 - g3, h, i) for case 20110614 at Qingpu of Shanghai. 
(d1)

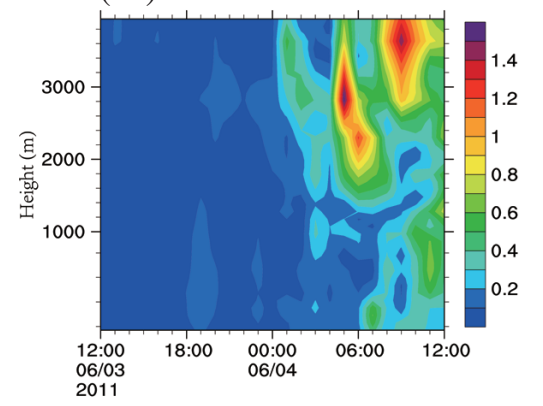

(e)

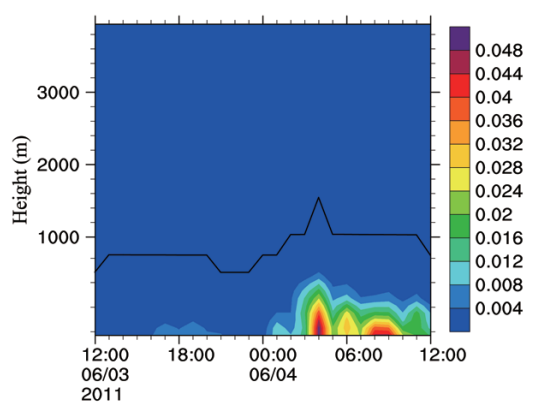

(d3)

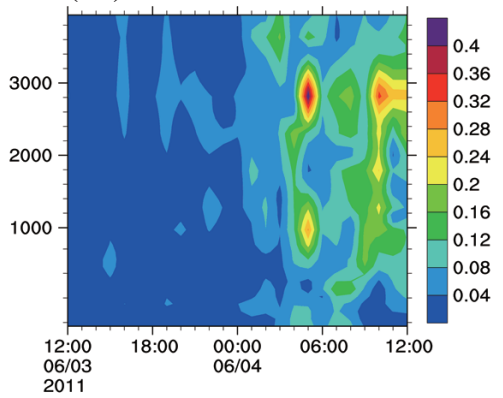

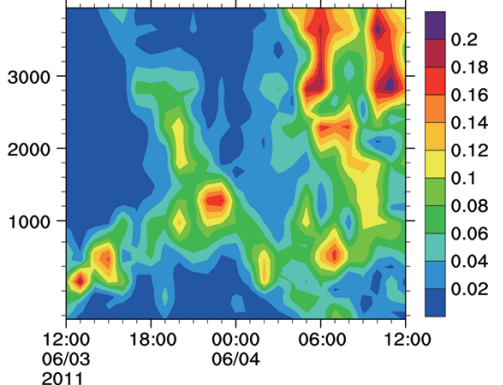

(f)

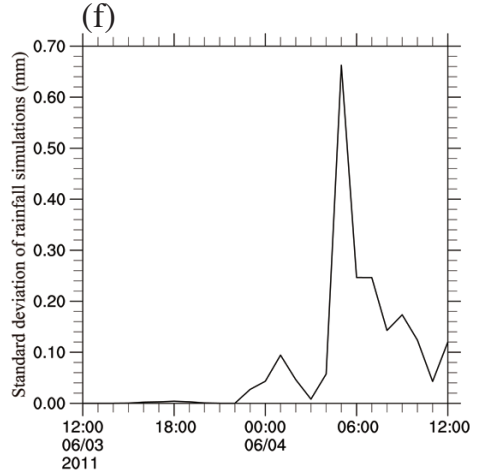

(g1)

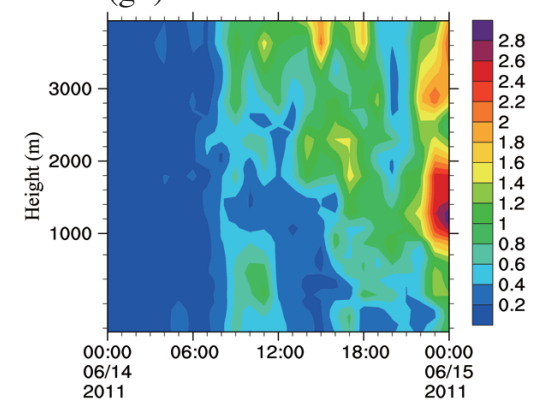

(h)

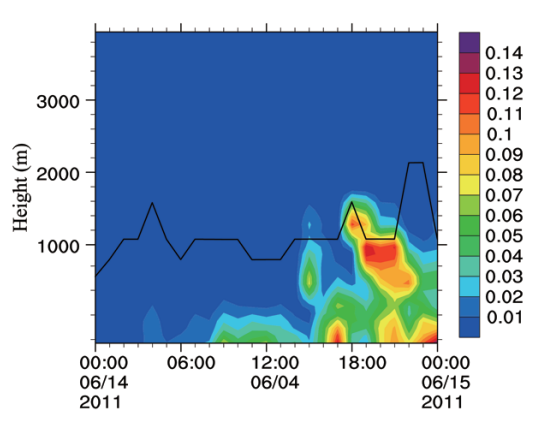

(g2)

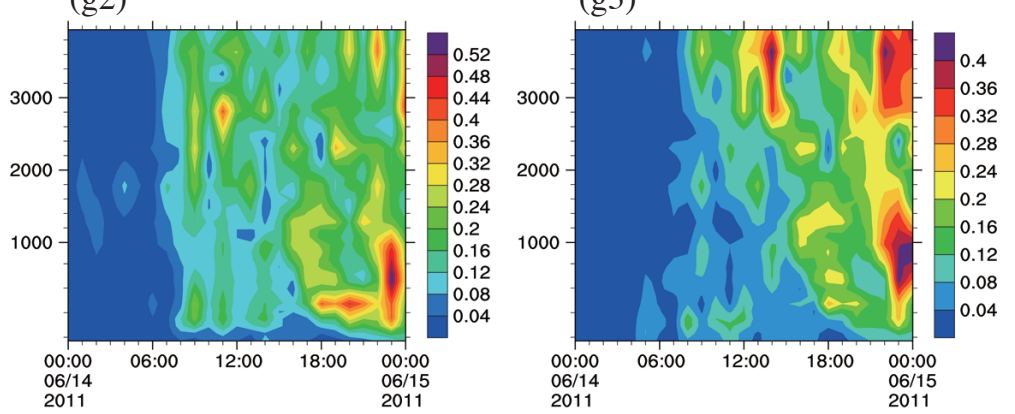

(i)

Fig. 4. (Continued)

(Figs. 4a1 - b), and the past 1-hour rainfall also shows sensitivities to the parameters (Fig. 4c). The standard deviation of wind speed in the PBL is as high as $1 \mathrm{~m} \mathrm{~s}^{-1}$ during that time, that of potential temperature is as high as $0.3^{\circ} \mathrm{C}$ and that of water vapor mixing ratio is as high as $0.5 \mathrm{~g} \mathrm{~kg}^{-1}$. From 0300 UTC 4 June to 1200 UTC 4 June 2011 for case 20110604 (Figs. 4d1 - f), both PBL variables and TKE show obvious sensitivities to the parameters (Figs. $4 \mathrm{~d} 1$ - f), and the past 1-hour rainfall also shows sensitivities to the parameters (Fig. 4f). The standard deviation of wind speed in the PBL is as high as $0.5 \mathrm{~m} \mathrm{~s}^{-1}$ during that time, that of potential temperature is as high as $0.12^{\circ} \mathrm{C}$ and that of water vapor mixing ratio is as high as $0.14 \mathrm{~g} \mathrm{~kg}^{-1}$. From 1600 UTC 14 June to 0000 UTC 15 June 2011 for case 20110614 (Figs. 4g - i), both PBL variables and TKE show obvious sensitivities to the parameters (Figs. 4g1 - i), and the past 1-hour rainfall also 
shows sensitivities to the parameters (Fig. 4i). The standard deviation of wind speed in the PBL is as high as $1.2 \mathrm{~m} \mathrm{~s}^{-1}$ during that time, that of potential temperature is as high as $0.52^{\circ} \mathrm{C}$ and that of water vapor mixing ratio is as high as $0.4 \mathrm{~g} \mathrm{~kg}^{-1}$. This implies that parameters may alter PBL physical quantity (momentum, heat, and moisture) transfers by changing turbulence vertical mixing, which then affect rainfall. During the above three periods for the three cases, wind speed, potential temperature and water vapor mixing ratio show much greater sensitivities above PBL compared with that in PBL. This indicates that PBL processes affect rainfall by coupling with other physical processes, such us cumulus convection. From 1200 UTC 23 July to 1800 UTC 23 July 2009, both mean wind speed, potential temperature, water vapor mixing ratio and TKE show much weaker sensitivities to the parameters (Figs. 4a1, a3 - b) than that of the period from 0000 UTC 24 July to 1100 UTC 24 July 2009 , but 1-hour rainfall show much greater sensitivities to the parameters (Figs. 4a2, c). This suggests that parameters may affect the rainfall amount or intensity by changing the physical quantity (momentum, heat, and moisture) transfer and turbulent mixing. However, to what degree the parameters influence the amount of precipitation may be related to the specific synoptic pattern and other physical processes (such us cumulus parameterizations). During the time from 1400 UTC 23 July to 1600 UTC 23 July 2009, mean wind speed and water vapor mixing ratio show much weaker sensitivities than that of during the period from 0500 UTC 24 July to 0700 UTC 24 July 2009 (the maximum values of standard deviation of wind speed and water vapor mixing ratio during the time from 1400 UTC 23 July to 1600 UTC 23 July 2009 are less than half of that during the period from 0500 UTC 24 July to 0700 UTC 24 July 2009), but potential temperature does not show so much weaker sensitivities accordingly (the maximum values of standard deviation for potential temperature during the time from 1400 UTC 23 July to 1600 UTC 23 July 2009 are much more than half of that during the period from 0500 UTC 24 July to 0700 UTC 24 July 2009), indicating that the relative importance of those physical quantity transfers (heat transfer, momentum transfer or moisture transfer) during a rainfall may depend on the specific PBL structure and meteorological circumstances.

For case 20090723 the wind speeds measured from the WP are available at heights of 171, 231, 291, 351, 412, 472, 532, $592 \mathrm{~m}$ at Jiading in Shanghai and the simulated wind speeds are interpolated to those levels. For cases 20110604 and 20110614 the measured WP speeds are available at heights of 187, 290, 392, 495, $597 \mathrm{~m}$ at Qingpu of Shanghai and the simulated wind speed is interpolated to those levels. According to the mean absolute bias formula provided in the above section, Table 2 shows the 24-hour mean absolute wind speed bias averaged over the remaining 24-hour of each simulation for all three cases (20090723, 20110604, and 20110614). The mean absolute bias averaged over the three cases shows that none of these schemes is always the best.

\subsection{PBL Structures}

The direct way to investigate moisture, heat and other physical quantity transportation in the PBL is by inspecting the temperature and moisture profiles. The data obtained from radiosonde soundings are used to evaluate the predicted temperature and water vapour mixing ratio profiles. Figures $5 \mathrm{a}-\mathrm{b}$ show potential temperature and water vapor mixing ratio profiles simulated by QMYJ PBL schemes (QMYJ0.7 - 1.2) due to different MYJ parameters for the three Lower Yangtze River cases.

The simulated water vapor mixing ratio and potential temperature profiles corresponding to sounding measurements at 0000 UTC 24 July 2009 , at the Hangzhou $\left(120.17^{\circ} \mathrm{E}\right.$, $30.23^{\circ} \mathrm{N}$ ) site are presented in Figs. 5a and b. All experiments overestimated the water vapor mixing ratio below $900 \mathrm{hPa}$ and underestimated the potential temperature below $965 \mathrm{hPa}$. All simulations underestimated the inversion layer stability (Figs. 5a snd b). All experiments failed to simulate the unstable layer below $965 \mathrm{hPa}$ and also failed to simulate dry intrusion characteristics in the PBL (Fig. 5b). The inaccurate planetary boundary layer simulations could eventually affect rainfall. On the one hand, acting as a cap, the inversion layer is conducive to heat and water accumulation. Once the cap is broken violent convection may occur, often leading to shorttime severe precipitation. Thus, underestimating inversion stability may lead to decreased precipitation (Fig. 5c). On the other hand, dry intrusion in PBL strengthens the statistical instability stratification, which favors rainfall. Thus, failing to simulate dry intrusion may result in underestimating rainfall (Fig. 5c). Although overestimating moisture may lead to overestimating rainfall, rainfall is still under-predicted if inversion instability is underestimated and failure to simulate dry intrusion plays a main role. Those experiments simulated different water vapor mixing ratio bias below $965 \mathrm{hPa}$ and above PBL, but simulated almost the same potential temperature and water vapor mixing ratio between 965 and $900 \mathrm{hPa}$. TKE shows large sensitivities at about 2100 UTC 23 July 2009 (not shown), which lags behind the time 0000 UTC 24 July 2009 when strong rainfall occurred (Fig. 5c). The W-component of the wind speed also shows large sensitivities during the strong rainfall period (not shown). There are two reasons that may account for this phenomenon. First$1 y$, the PBL parameters may alter the vertical velocity and super-low level water vapor convergence by affecting turbulent mixing, thus bringing increased or decreased precipitation. Secondly, the parameters may alter turbulent mixing by coupling with other physical schemes (such as cumulus parameterization), then alter the moisture transfer above PBL, finally affecting precipitation.

For the 20110604 case (Figs. 5d and e), all experiments simulated the SBL and overestimated the stability below 
$900 \mathrm{hPa}$. Those simulations underestimated water vapor mixing ratio below $740 \mathrm{hPa}$ and overestimated it above $740 \mathrm{hPa}$. Moisture overestimation above PBL may lead to cumulus precipitation over-prediction, but overestimated PBL stability, leading to cumulus precipitation under prediction. Thus, total rainfall precipitation is under-predicted if stability overstimation plays a main role (see Fig. $5 f$ the period from 2000 UTC 3 June to 0300 UTC 4 June 2011), and vice versa, total rainfall precipitation is over-predicted if moisture overestimation plays a main role (see Fig. $5 \mathrm{f}$ the period from 0900 UTC 4 June to 1200 UTC 4 June 2011). Compared with the other two cases the potential temperature and water vapor mixing ratio at Hangzhou site show less sensitivity to the PBL parameters. This may be attributed to the weaker turbulent mixing sensitivities during the rainfall period (not shown). The 24 accumulated rainfalls for the 20110604 case were also smaller than the other two cases, which indicates PBL turbulent mixing is closely related to the rainfall.

In the 20110614 case (Figs. 5g and h) all experiments simulated the SBL well and underestimated potential temperatures below $850 \mathrm{hPa}$. They also underestimated the water vapor mixing ratio below $850 \mathrm{hPa}$ and overestimated it above (a)

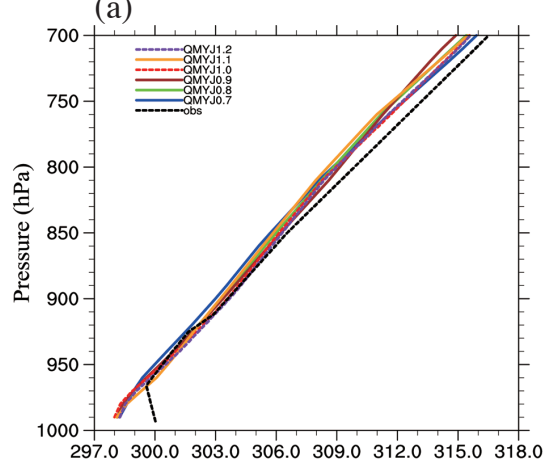

(d)

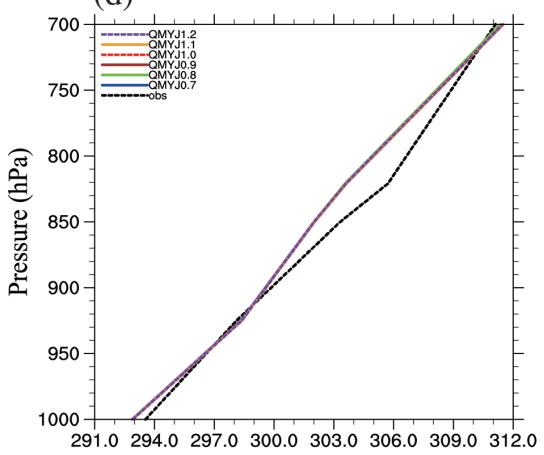

(g)

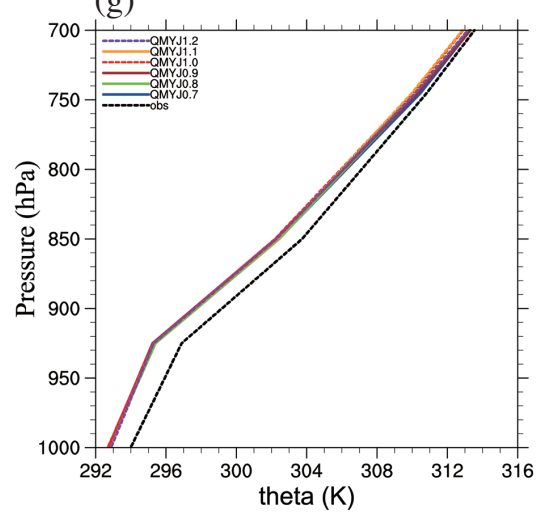

(b)

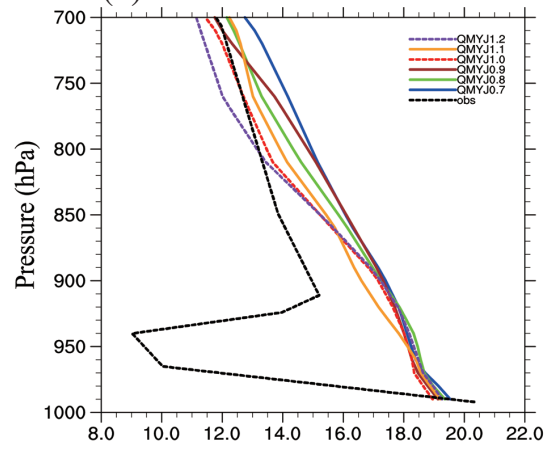

(e)

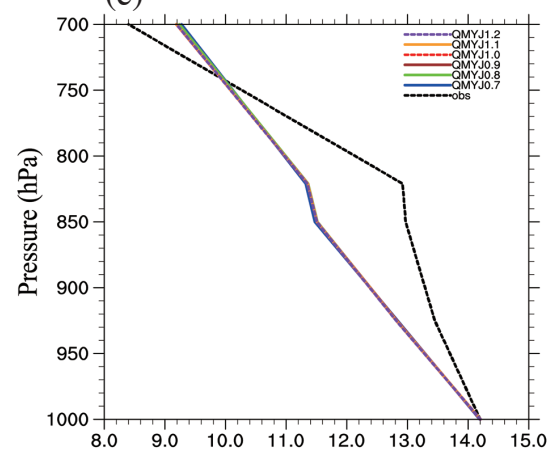

(h)

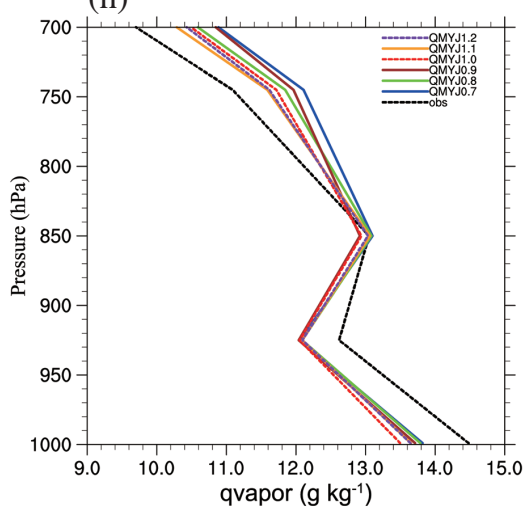

(c)

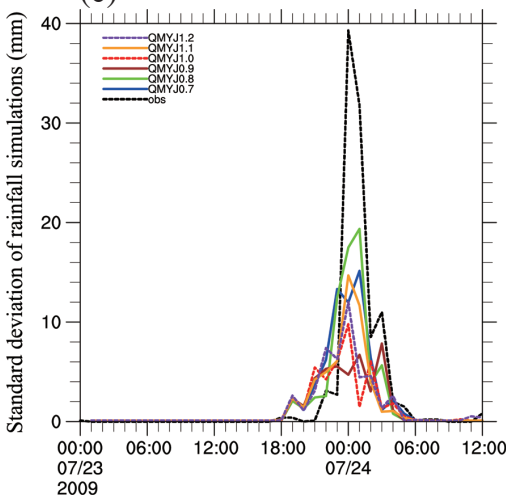

(f)
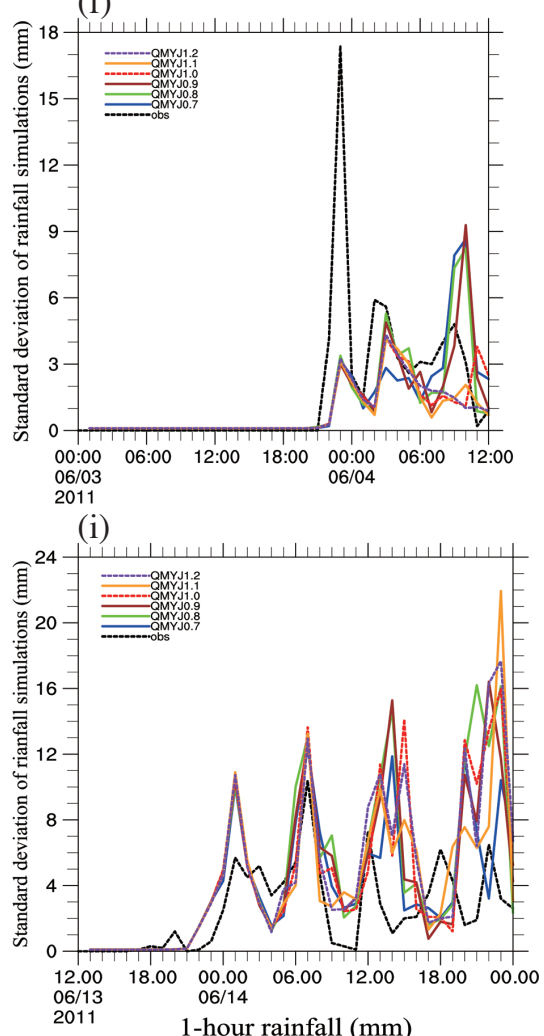

Fig. 5. Mean profiles of potential temperature (a), water vapor mixing ratio (b) at 0000 UTC 24 July 2009, and 1-hour rainfall (c) at Hangzhou $\left(120.17^{\circ} \mathrm{E}, 30.23^{\circ} \mathrm{N}\right)$ site; mean profiles of potential temperature (d) and water vapour mixing ratio (e) at 0000 UTC 4 June 2011 , and 1-hour rainfall (f) at Hangzhou site; mean profiles of potential temperature (g) and water vapour mixing ratio (h) at 1200 UTC 14 June 2011, and 1-hour rainfall (i) at Hangzhou site from observations (black) and parameter simulations: the QMYJ0.7 (blue), the QMYJ0.8 (green), the QMYJ0.9 (brown), the QMYJ (red), the QMYJ1.1 (yellow), the QMYJ1.2 (purple). 
that altitude. The inversion layer is inductive to energy accumulation and once the cap is broken all of the energy will be released. Thus, overestimating inversion layer stability may lead to overestimating the unstable energy, leading to rainfall overestimation. Overestimating the moisture in the troposphere may lead to cumulus precipitation over prediction. Thus, 1-hour rainfall precipitation is over-predicted (Fig. 5f) for cumulus precipitation occupying the main proportion of the total precipitation. Those experiments simulated different water vapor mixing ratios below $950 \mathrm{hPa}$. Nearly the same water vapor mixing ratio was simulated between 950 and $850 \mathrm{hPa}$. Turbulent mixing shows great sensitivities during the rainfall period from 0000 UTC 14 to 0000 UTC 15 . Those results imply that the parameters affect vertical moisture mixing in the lower PBL layer and may affect moisture transfer in the troposphere above PBL by coupling with other physical parameterizations (such as cumulus scheme), thus affecting precipitation.

For the 20090723 and 20110614 cases the mean vapor profiles show distinctively different bias in the lower PBL, implying that moisture transfer in the rainfall area is sensitive to the parameters in the lower PBL layer. Moisture and potential temperature show more discrepancies above PBL than in PBL, which is consistent with the conclusion drawn in the above section. For the 20110604 case moisture and potential temperature show weaker sensitivities compared with those for the other two cases. This may be attributed to weak turbulent mixing in the boundary layer for case 20110604. It is the same case compared with the 20110614 and 20090723 cases. These results may imply that the parameters sensitivity is positively related to the rainfall and turbulent mixing strength. The above analysis implies that parameters affect rainfall possibly in this way: the parameters alter low level moisture convergence by changing turbulence mixing, thus parameter sensitivity is related to turbulent mixing strength. Parameters affect turbulent mixing by coupling with cumulus parameterization and then change moisture transfer above PBL, thus altering the rainfall. None of the parameters are always the best for potential temperature and moisture simulations, and may be the most suitable parameters for model simulations related to specific PBL structures depending on their meteorological and geophysical conditions.

\subsection{PBL Height}

The PBL height is an important variable in atmospheric numerical models, as it is used in other physics schemes when necessary (Shin and Hong 2011). PBL height can reflect turbulent mixing. Table 3 compares the PBL heights averaged over the different sites which almost located in a line. For case 20090723 those sites are Baoshan, Hangzhou, Shaowu, and Ganzhou (Fig. 1). For case 20110604 those sites are Sheyang, Nanjing, Anqing, Nanchang, and Chen- zhou (Fig. 1). For case 20110614 those sites are Shanghai, Hangzhou, Quzhou, Shaowu, and Longyan (Fig. 1). The diagnostic PBL heights are diagnosed from potential temperature and wind speed vertical profiles using the diagnostic approach described in section 3. The QMYJ scheme determines the PBL height using the TKE profile and PBL height is estimated as the height where the simulated TKE reaches a prescribed low value (Janjić 2001; Sukoriansky 2008).

In order to understand the model parameters effects on QMYJ PBL scheme rainfall simulations, Fig. 6 shows standard deviation of TKE (Figs. 6a, d, g), 1-hour rain (Figs. 6b, e, h) with respect to different MYJ parameters, compared with the standard PBL height deviation along a particular section across the rain sites for each case.

Figure 6a shows that standard deviation for TKE across $(25.85,114.95)$ and $(31.41,121.46)$ (Baoshan-Ganzhou section) shows different values, namely TKE shows different sensitivities over different rainfall areas. Overall, TKE is sensitive to parameters over the regions where rainfall shows high sensitivities to parameters (comparing Figs. 6a and b), and PBL height shows high sensitivities over the regions where TKE shows great sensitivities (comparing Figs. 6a and c). This phenomenon indicates the PBL parametes may alter rainfall by changing turbulent mixing, and the variations in PBL height can correctly reflect the variations in turbulent mixing. According to the terrain height over this section TKE is more probable to showing high sensitivities over mountain areas (the white shading in Figs. 6a, d, and g indicates terrain effect). This is the same case for the other two Lower Yangtze River cases (Figs. 6d - i). Table 3 shows that none of the parameters are always the best for the PBL height simulations.

In summary, parameters alter rainfall by changing turbulent mixing and turbulent mixing is more probable to show sensitivities in complex geophysical conditions. Table 3 shows that none of the MYJ parameters are always the optimal. The above results indicate that the optimal parameters should be defined properly according to PBL dynamics and thermal structures depending on the meteorological and geophysical circumstances.

\subsection{Precipitation Analysis from Model Results}

\subsubsection{Intercomparisons of Precipitation from Different Experiments}

Figures $7 \mathrm{a}$ and $\mathrm{b}$ show the 24-hour accumulated precipitation of the observation and simulations of six different experiments for the rainfall from 1200 UTC 23 July to 1200 UTC 24 July 2009. The 24-hour accumulated precipitation for observations distributed over the Lower Yangtze River in China, with a rainband stretching from west to east. There is heavy rainfall over Hubei and Anhui in the Lower Yangtze River regions. One rainfall center located at $\left(29.9^{\circ} \mathrm{N}, 117.9^{\circ} \mathrm{E}\right)$ near the Yi county of Huangshan in Anhui province with the maximum rainfall value exceeded $160 \mathrm{~mm}$. Another located 
at $\left(29.6^{\circ} \mathrm{N}, 114.5^{\circ} \mathrm{E}\right)$ near the Tongshan county of Xianning in Hubei province with the maximum rainfall value exceeded 100 $\mathrm{mm}$. These two rainfall centers are referred to as HS and TS respectively. All of the simulations correctly reproduced the synoptic situation by predicting the sea level pressure, $850 \mathrm{hPa}$ geopotential height field, $850 \mathrm{hPa}$ wind field and $850 \mathrm{hPa}$ temperature field. From the 24-hour accumulated precipitation for the observations and simulations (Figs. 7a and b), we can see that the spatial patterns of the simulations are very similar to that of the observations. There are pronounced differences in the range and intensity if we compare the precipitation centers (HS, TS) between the observations and the simulations. Slight differences could be seen in the north-south width and east-west trend of the rainband among the simulations with

Table 3. Mean absolute bias of PBL height (unit: $\mathrm{m}$ ) between simulations and diagnostic PBL height from measurements for the three cases.

\begin{tabular}{ccccccc}
\hline \multirow{2}{*}{ case } & \multicolumn{7}{c}{ QMYJ PBL schemes } \\
\cline { 2 - 7 } & QMYJ 0.7 & QMYJ 0.8 & QMYJ 0.9 & QMYJ & QMYJ 1.1 & QMYJ 1.2 \\
\hline 20090723 & $\mathbf{8 5 . 7}$ & 133.3 & 131.5 & 135.9 & 101.7 & 205.1 \\
20110604 & $\mathbf{2 9 7 . 7}$ & 311.4 & 307.6 & 299.5 & 307 & 326.7 \\
20110614 & 582.6 & 565.2 & 630 & 536.8 & $\mathbf{4 3 7 . 7}$ & 459.6 \\
\hline average & 322 & 336.6 & 356.4 & 324.1 & $\mathbf{2 8 2 . 1}$ & 330.5 \\
\hline
\end{tabular}

(a)

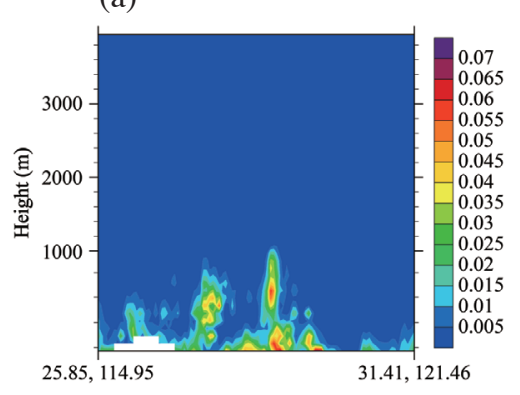

(d)

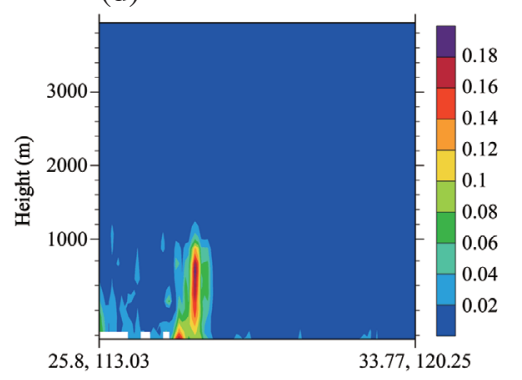

(g)

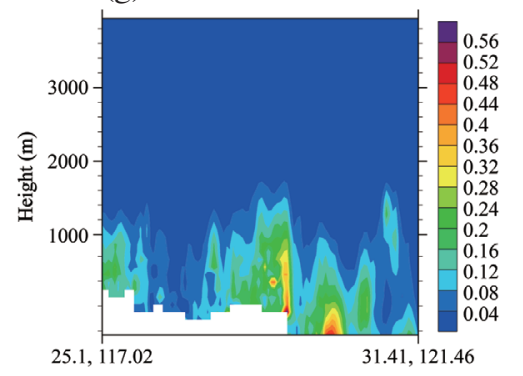

(b)

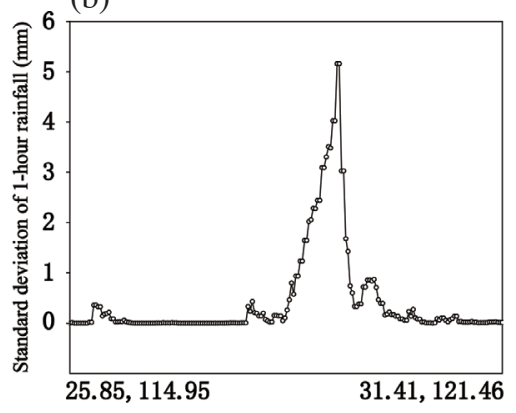

(e)

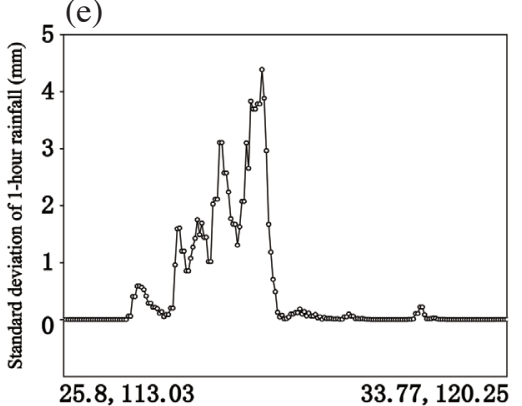

(h)

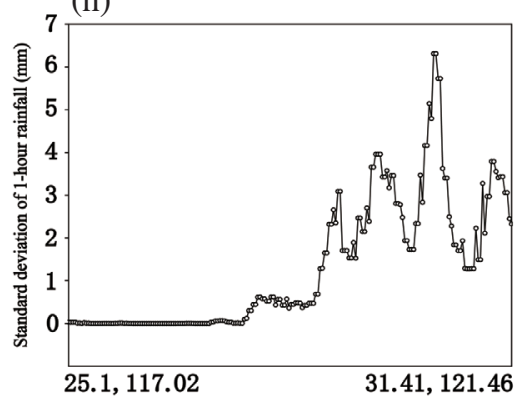

(c)

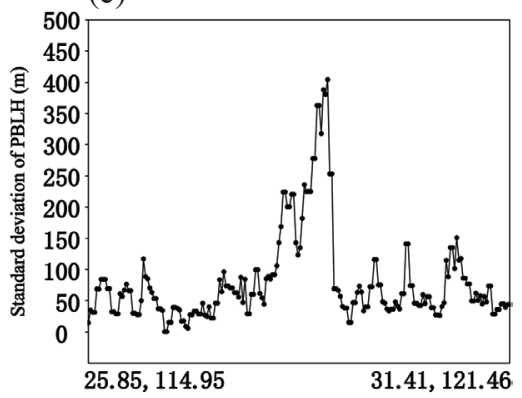

(f)

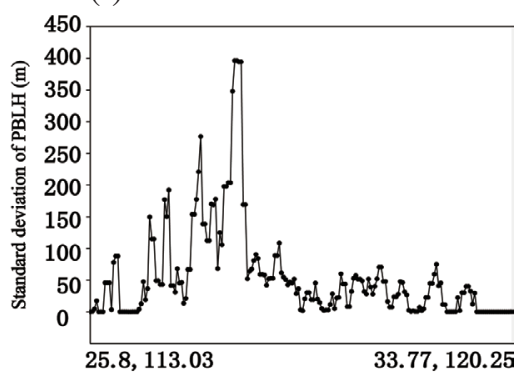

(i)

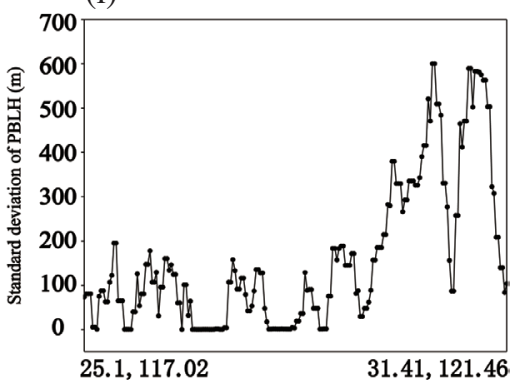

Fig. 6. Standard deviation of turbulent kinetic energy (a, d, g), 1-hour rain (b, e, h) and PBL heights (c, f, i) with respect to different MYJ parameters across particular sections at 1200 UTC, 24 July 2009, 1200 UTC, 4 June 2011, 0000 UTC, 15 June 2011 respectively for case 20090723 (top), for case 20110604 (middle), for case 20110614 (bottom). 

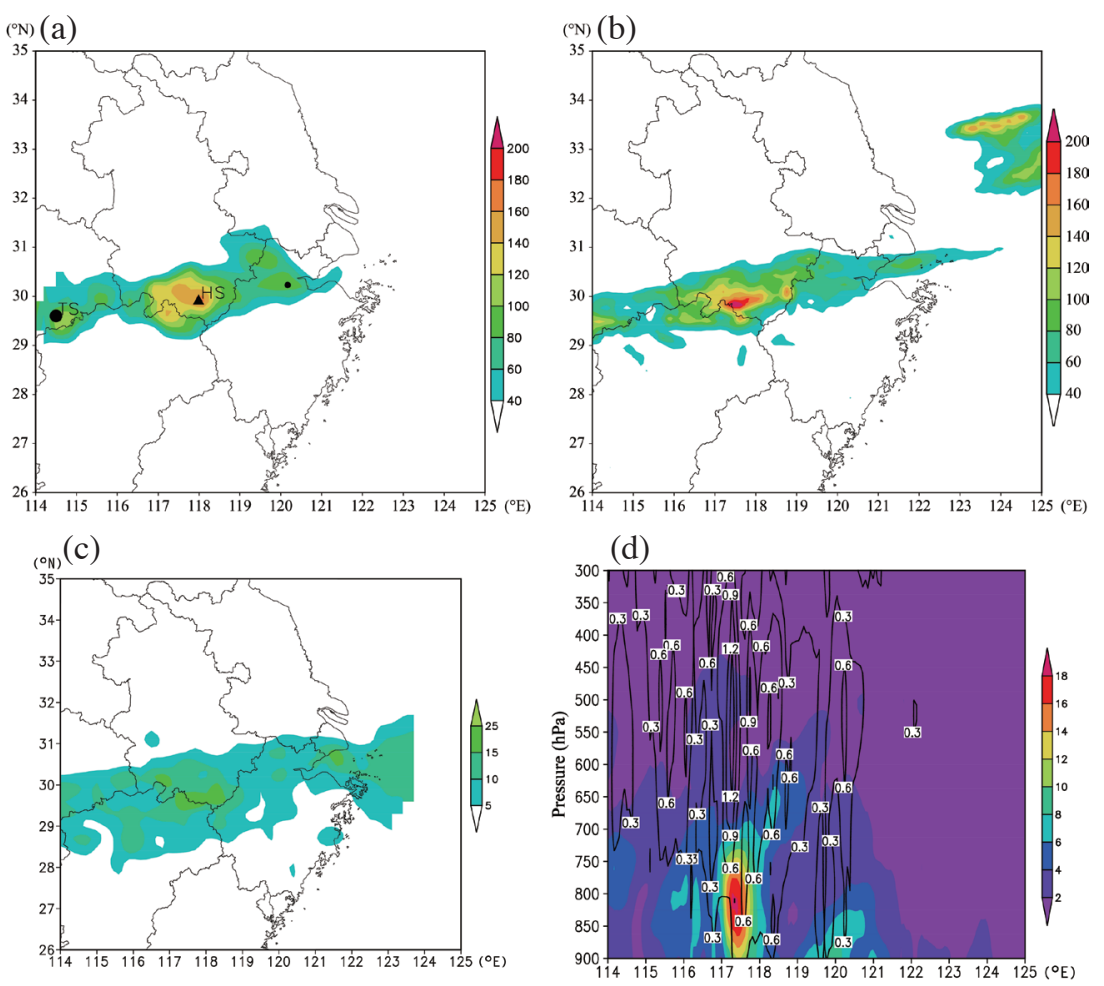

Fig. 7. 24-hour accumulated precipitation (mm) for observation and QMYJ simulations: (a) observation, (b) QMYJ. TS denotes Tongshan in Hubei province, HS denotes Huangshan in Anhui province. (c) Standard deviation of 24-hour accumulated precipitation with respect to different MYJ parameters. (d) Standard deviation of water vapor mixing ratio (shaded, unit: $\mathrm{g} \mathrm{kg}^{-1}$ ) and vertical velocity (contours, unit: $\mathrm{m} \mathrm{s}^{-1}$ ) with respect to different MYJ parameters across $29.5^{\circ} \mathrm{N}$ at 1300 UTC, 23 July 2009.

six different treatments of MYJ parameters. The model runs successfully reproduced the center HS, though the precipitation center TS was not well reproduced.

Figure $7 \mathrm{c}$ shows that the rainfall simulations show different parameter sensitivities in different rainfall regions and the sensitivities over strong rainfall areas (near HS) are stronger than those over weak rainfall areas. This may be attributed to different turbulent mixing strength in different rainfall areas under different geophysical circumstances. By coupling with other physical processes (such as cumulus convection processes), leading to more different moisture and momentum transport (Fig. 7d), similar conclusions can be drawn by analyzing the other two cases.

In order to get the quantitative differences in rainfall simulation sensitivity to the MYJ parameters $\left(A_{1}, A_{2}, B_{1}, B_{2}\right.$, $C_{1}$ ) in QMYJ scheme over the Lower Yangtze River region, it is necessary to verify precipitation forecasts using statistical verification (threat score and hit rate methods). Detail information about verification methods can be seen in Stanski et al. (1989).

\subsubsection{Statistical Verification of Precipitation}

Tables 4,5 , and 6 show the verification results for the 24-hour accumulated rainfall from 1200 UTC 23 July to
1200 UTC 24 July 2009, from 1200 UTC 3 June to 1200 UTC 4 June 2011, and from 0000 UTC 14 June to 0000 UTC 15 June 2011 respectively. Parameters show non-distinctive differences for the thresholds of $0.1 \mathrm{~mm}$ and show obvious differences for the thresholds of more than $50 \mathrm{~mm}$ in Ts and Eh (Tables 4 - 6). This indicates that sensitivities for strong rainfalls are higher than those for weak rainfalls, which is in agreement with the previously mentioned results concluded by Fig. 7c. This implies that the parameters sensitivity is positively related to the rainfall strength. However, none of the parameters are always the best and the reasonable choice of parameters may depend on the specific dynamics and thermal structures in different geophysical and meteorological circumstances.

Overall, there are pronounced differences in the precipitation center among the six QMYJ experiments. However, there are unpronounced differences in the precipitation among the six QMYJ experiments. Precipitation forecasts from the six experiments look very similar in Fig. 7 and the changes in statistical scores are only within a few percentages (Tables 4 - 6). In order to know such changes can be considered as significant effects, this paper conducted rainfall simulations with other PBL schemes (MYJ, MYNN2.5, MYNN3, YSU, ACM2, Boulac), and compared their differences with the differences among the six QMYJ experiments. Table 7 
Table 4. Verification results for the 24-hour accumulated rainfall occurred from 1200 UTC 23 July to 1200 UTC 24 July 2009.

\begin{tabular}{cccccccc}
\hline Verification methods & Threshold (mm) & QMYJ 0.7 & QMYJ 0.8 & QNSE 0.9 & QNSE & QNSE 1.1 & QNSE 1.2 \\
\hline \multirow{3}{*}{ Threat Score } & $\geq 0.1$ & 0.9736 & 0.9749 & $\mathbf{0 . 9 7 7 8}$ & 0.9775 & $\mathbf{0 . 9 7 7 8}$ & 0.9775 \\
& $\geq 50$ & 0.5574 & $\mathbf{0 . 6 1 6 4}$ & 0.499 & 0.5378 & 0.5495 & 0.5407 \\
& $\geq 100$ & $\mathbf{0 . 4 9 2 1}$ & 0.4322 & 0.3939 & 0.4462 & 0.4595 & 0.4074 \\
& $\geq 150$ & 0.2889 & 0.2973 & 0.2292 & 0.2195 & $\mathbf{0 . 3 0 5 6}$ & 0.1957 \\
\hline \multirow{2}{*}{ Hit Rate } & $\geq 0.1$ & 0.9736 & 0.9749 & $\mathbf{0 . 9 7 7 8}$ & 0.9775 & $\mathbf{0 . 9 7 7 8}$ & 0.9775 \\
& $\geq 50$ & 0.8529 & $\mathbf{0 . 8 7 9 3}$ & 0.8401 & 0.8522 & 0.8545 & 0.8545 \\
& $\geq 100$ & $\mathbf{0 . 9 6 8 7}$ & 0.9631 & 0.9608 & 0.9664 & 0.9674 & 0.9635 \\
& $\geq 150$ & 0.9896 & 0.9915 & 0.9879 & 0.9896 & $\mathbf{0 . 9 9 1 8}$ & 0.9879 \\
\hline
\end{tabular}

Table 5. Verification results for the 24-hour accumulated rainfall occurred from 1200 UTC 3 June to 1200 UTC 4 June.

\begin{tabular}{cccccccc}
\hline Verification methods & Threshold $(\mathbf{m m})$ & QMYJ 0.7 & QMYJ 0.8 & QMYJ 0.9 & QMYJ & QMYJ 1.1 & QMYJ 1.2 \\
\hline \multirow{2}{*}{ Threat Score } & $\geq 0.1$ & 0.9584 & 0.9584 & 0.9577 & 0.9582 & $\mathbf{0 . 9 5 8 8}$ & 0.9582 \\
& $\geq 50$ & $\mathbf{0 . 2 8 4 2}$ & 0.2838 & 0.2597 & 0.2633 & 0.2824 & 0.261 \\
\hline \multirow{2}{*}{ Hit Rate } & $\geq 0.1$ & 0.9584 & 0.9584 & 0.9577 & 0.9582 & $\mathbf{0 . 9 5 8 8}$ & 0.9582 \\
& $\geq 50$ & 0.8228 & 0.8263 & 0.8245 & 0.8338 & $\mathbf{0 . 8 3 8 7}$ & 0.8312 \\
\hline
\end{tabular}

Table 6. Verification results for the 24-hour accumulated rainfall occurred from 0000 UTC 14 June to 0000 UTC 15 June 2011.

\begin{tabular}{cccccccc}
\hline Verification methods & Threshold $(\mathbf{m m})$ & QMYJ 0.7 & QNSE 0.8 & QNSE 0.9 & QNSE & QNSE 1.1 & QNSE 1.2 \\
\hline \multirow{2}{*}{ Threat Score } & $\geq 0.1$ & 0.6423 & 0.6436 & 0.6447 & 0.643 & $\mathbf{0 . 6 4 6 8}$ & 0.6431 \\
& $\geq 50$ & 0.5136 & 0.5253 & 0.5181 & 0.509 & $\mathbf{0 . 5 3 8 1}$ & 0.5222 \\
& $\geq 100$ & 0.3801 & 0.3689 & 0.3537 & 0.3841 & $\mathbf{0 . 3 8 4 8}$ & $\mathbf{0 . 3 8 4 8}$ \\
& $\geq 150$ & $\mathbf{0 . 1 4 0 9}$ & 0.1391 & 0.1345 & 0.1118 & 0.1216 & 0.1166 \\
\hline \multirow{2}{*}{ Hit Rate } & $\geq 0.1$ & 0.6567 & 0.6593 & 0.6607 & 0.6579 & $\mathbf{0 . 6 6 2 8}$ & 0.6582 \\
& $\geq 50$ & 0.8573 & 0.8658 & 0.862 & 0.8575 & $\mathbf{0 . 8 7 1 9}$ & 0.8634 \\
& $\geq 100$ & 0.923 & 0.9227 & 0.9181 & 0.9248 & $\mathbf{0 . 9 2 5 4}$ & $\mathbf{0 . 9 2 5 4}$ \\
& $\geq 150$ & 0.9704 & 0.9664 & $\mathbf{0 . 9 7 2 5}$ & 0.9670 & 0.9700 & 0.9667 \\
\hline
\end{tabular}

Table 7. Ratio of standard deviation for threat score between the seven different schemes (MYJ, MYNN2.5, MYNN3, YSU, ACM2, Boulac) and the six QMYJ experiments.

\begin{tabular}{|c|c|c|c|c|}
\hline Verification methods & Threshold (mm) & 2009072312 & 2011061400 & 2011060312 \\
\hline \multirow{4}{*}{ Threat Score } & $\geq 0.1$ & $57.31 \%$ & $13.32 \%$ & $2.84 \%$ \\
\hline & $\geq 50$ & $31.83 \%$ & $17.18 \%$ & $14.69 \%$ \\
\hline & $\geq 100$ & $19.60 \%$ & $19.12 \%$ & /II \\
\hline & $\geq 150$ & $43.79 \%$ & $20.80 \%$ & //I \\
\hline \multirow{4}{*}{ Hit Rate } & $\geq 0.1$ & $57.31 \%$ & $11.41 \%$ & $3.02 \%$ \\
\hline & $\geq 50$ & $32.40 \%$ & $15.79 \%$ & $14.71 \%$ \\
\hline & $\geq 100$ & $21.67 \%$ & $10.56 \%$ & /II \\
\hline & $\geq 150$ & $95.98 \%$ & $40.29 \%$ & /// \\
\hline
\end{tabular}


shows the ratio of standard deviation between the threat score for the seven different schemes and the six QMYJ experiments. Four thresholds are given for quantitative precipitation verifications: they are $0.1,50,100,150 \mathrm{~mm}$, representing different grades of rainfall strength. Thus, the impacts of the MYJ parameters can be quantified. The rainfall change due to the MYJ parameters is more than $10 \%$ of the change due to the different PBL schemes, except the ratio of standard deviation for the threat score and hit rate score of $0.1 \mathrm{~mm}$ threshold for case 20110604. As mentioned above in PBL structures, water vapor mixing ratio and potential temperature of case 20110604 show less sensitivities compared with the other two cases. The parameters show slight effects on the rainfall of case 20110604, the reason for it may be that weak rainfalls with weak turbulent mixing occupy the main part and pull down the parameters sensitivities. The results indicate that parameters sensitivity may be positively correlated with rainfall intensity and turbulent mixing strength.

\section{CONCLUSIONS}

A series of experiments using three Lower Yangtze River rainfall simulations were conducted in this study using the QMYJ PBL schemes with different MYJ parameter $\left(A_{1}, A_{2}, B_{1}, B_{2}, C_{1}\right)$ values in the WRFV3.1.1 simulation program. The simulations tested the parameter sensitivities in comparison with the observations. The QMYJ scheme simulations using various parameter values were compared against each other.

The MYJ parameters played an important role in rainfall simulations in the Lower Yangtze River regions. The analysis results indicate that the MYJ parameters sensitivities to the rainfall amounts were related closely to the physical quantity (heat, moisture and momentum) transfers and turbulent mixing, however, which quantity transfer played the more important role depended on the specific meteorological conditions.

Generally speaking, rainfall strength, PBL height, wind speed, and water vapor mixing ratio showed great sensitivities to the parameters during strong rainfall periods, accompanied by obvious TKE variations. Wind speed, potential temperature and moisture showed much greater sensitivities above PBL. PBL parameters may affect turbulent mixing and physical quantity (momentum, moisture and heat) transfer, and then alter low-level physical quantity convergence by coupling with cumulus parameterization, thus altering rainfall. Turbulent mixing can be reflected by PBL structures depending on the geophysical and meteorological conditions. None of the parameters were always the best, indicating that different MYJ parameter values should be designated depending on the PBL structures under different geophysical and meteorological circumstances. To extract significant information from observations to adjust the model state, model parameter calibration using the ensemble
Kalman filter (EnKF) parameter estimation approach has been popular (Tong and Xue 2008a, b; Hu et al. 2010a; Jung et al. 2010). It may be acceptable to revise MYJ parameters using the EnKF parameter estimation method.

Although we arrived at some meaningful conclusions with the WRFV3.1.1 configuration and particular simulated cases in the Lower Yangtze River regions, there are limitations in this study. Firstly, the vertical resolution used in the WRF model is too coarse. Secondly, the rainfall cases used to analyze parameter sensitivities are limited; more cases may be needed. Ongoing study will choose more cases with high-resolution set in the model levels in the future to further confirm the above conclusions.

Acknowledgements This work was kindly and generally supported by the National Natural Science Foundation of China (41175047), the China Meteorological Administration Special Public Welfare Research Fund (GYHY201006014), National Basic Research and Development (973) Program of China (2013CB430100) and Basic Research Project of the State Key Laboratory of Severe Weather, Chinese Academy of Meteorological Sciences (12011LAS-B14). The profiler data at Shanghai station was kindly provided by Wang Zhi.

\section{REFERENCES}

Bonner, W. D., 1968: Climatology of the low level jet. Mon. Weather Rev., 96, 833-850, doi: 10.1175/1520-0493(1 968)096<0833:COTLLJ>2.0.CO;2. [Link]

Dudhia, J., 1989: Numerical study of convection observed during the winter monsoon experiment using a mesoscale two-dimensional model. J. Atmos. Sci., 46, 3077-3107, doi: 10.1175/1520-0469(1989)046<3077: NSOCOD $>2.0 . C O ; 2$. [Link]

Dudhia, J., 1996: A multi-layer soil temperature model for MM5. Preprints, $6^{\text {th }}$ Annual MM5 Users Workshop, Boulder, CO: 49-50.

Foken, T., 2006: 50 years of the Monin-Obukhov similarity theory. Bound.-Layer Meteor., 119, 431-447, doi: 10.1007/s10546-006-9048-6. [Link]

Galperin, B., S. Sukoriansky, and J. Pergaud, 2010: Current state of QNSE PBL model in WRF. The Third International Workshop on Next-Generation NWP Models at 29 August -1 September 2010 Jeju Island, Korea.

Gowen, R. A. and J. W. Smith, 1968: Turbulent heat transfer from smooth and rough surfaces. Int. J. Heat Mass Tran., 11, 1657-1674, doi: 10.1016/00179310(68)90046-X. [Link]

Grell, G. A. and D. Dévényi, 2002: A generalized approach to parameterizing convection combining ensemble and data assimilation techniques. Geophys. Res. Lett., 29, 38-1-38-4, doi: 10.1029/2002GL015311. [Link]

Hu, X. M., F. Zhang, and J. W. Nielsen-Gammon, 2010a: Ensemble-based simultaneous state and parameter 
estimation for treatment of mesoscale model error: A real-data study. Geophys. Res. Lett., 37, L08802, doi: 10.1029/2010GL043017. [Link]

Hu, X. M., J. W. Nielsen-Gammon, and F. Zhang, 2010b: Evaluation of three planetary boundary layer schemes in the WRF model. J. Appl. Meteorol. Climatol., 49, 1831-1844, doi: 10.1175/2010JAMC2432.1. [Link]

$\mathrm{Hu}, \mathrm{Y}$. and H. Zuo, 2003: The influence of convergence movement on turbulent transportation in the atmospheric boundary layer. Adv. Atmos. Sci., 20, 794-798, doi: 10.1007/BF02915404. [Link]

Hong, S. Y., J. Dudhia, and S. H. Chen, 2004: A revised approach to ice microphysical processes for the bulk parameterization of clouds and precipitation. Mon. Weather Rev., 132, 103-120, doi: 10.1175/1520-0493(2004)132<0103:ARATIM>2.0.CO;2. [Link]

Janjić, Z. I., 1994: The step-mountain eta coordinate model: Further developments of the convection, viscous sublayer, and turbulence closure schemes. Mon. Weather Rev., 122, 927-945, doi: 10.1175/1520-0493(1994)122 $<0927$ :TSMECM>2.0.CO;2. [Link]

Janjić, Z. I., 2001: Nonsingular implementation of the Mellor-Yamada level 2.5 scheme in the NCEP MESO model. NCEP Office Note, No. 437, 61 pp.

Jung, Y., M. Xue, and G. Zhang, 2010: Simultaneous estimation of microphysical parameters and the atmospheric state using simulated polarimetric radar data and an ensemble Kalman filter in the presence of an observation operator error. Mon. Weather Rev., 138, 539-562, doi: 10.1175/2009MWR2748.1. [Link]

Kestin, J. and P. D. Richardson, 1961: Heat transfer across turbulent incompressible boundary layers. Colloque International sur la Mdcanique de la Turbulence, Marseille, Editions du Centre National de la Recherche Scientifique, Paris.

Liu, S. and X.Z. Liang, 2010: Observed diurnal cycle climatology of planetary boundary layer height. J. Climate, 23, 5790-5809, doi: 10.1175/2010JCLI3552.1. [Link]

Mellor, G. L. and T. Yamada, 1974: A hierarchy of turbulence closure models for planetary boundary layers. $J$. Atmos. Sci., 31, 1791-1806, doi: 10.1175/1520-0469(1974)031<1791:AHOTCM>2.0.CO;2. [Link]

Mellor, G. L. and T. Yamada, 1982: Development of a turbulence closure model for geophysical fluid problems. Rev. Geophys., 20, 851-875, doi: 10.1029/ RG020i004p00851. [Link]

Mlawer, E. J., S. J. Taubman, P. D. Brown, M. J. Iacono, and S. A. Clough, 1997: Radiative transfer for inhomogeneous atmospheres: RRTM, a validated correlated-k model for the longwave. J. Geophys. Res., 102, 1666316682, doi: 10.1029/97JD00237. [Link]

Moeng,C.H.andJ.C.Wyngaard,1989:Evaluationofturbulent transport and dissipation closures in second-order modeling. J.Atmos. Sci., 46, 2311-2330, doi: 10.1175/1520-
0469(1989)046<2311:EOTTAD>2.0.CO;2. [Link]

Nielsen-Gammon, J. W., X. M. Hu, F. Zhang, and J. E. Pleim, 2010: Evaluation of planetary boundary layer scheme sensitivities for the purpose of parameter estimation. Mon. Weather Rev., 138, 3400-3417, doi: 10.1175/2010MWR3292.1. [Link]

Pleim, J. E., 2007a: A combined local and nonlocal closure model for the atmospheric boundary layer. Part I: Model description and testing. J. Appl. Meteorol.Climatol., 46, 1383-1395, doi: 10.1175/JAM2539.1. [Link]

Pleim, J. E., 2007b: A combined local and nonlocal closure model for the atmospheric boundary layer. Part II: Application and evaluation in a mesoscale meteorological model. J. Appl. Meteorol. Climatol., 46, 1396-1409, doi: 10.1175/JAM2534.1. [Link]

Schlichting, H., 1979: Boundary-Layer Theory, $7^{\text {th }}$ Ed., McGraw-Hill Higher Education, New York, 705-708.

Shin, H. H. and S. Y. Hong, 2011: Intercomparison of planetary boundary-layer parametrizations in the WRF model for a single day from CASES-99. Bound.-Layer Meteor., 139, 261-281, doi: 10.1007/s10546-010-9583-z. [Link]

Skamarock, W. C., J. B. Klemp, J. Dudhia, D. O. Gill, D. M. Barker, M. G. Duda, X. Y. Huang, W. Wang, and J. G. Powers, 2008: A description of the advanced research WRF version 3. NCAR Technical Note NCAR/ TN-475+STR, Mesoscale and Microscale Meteorology Division, National Center for Atmospheric Research, Boulder, Colorado, USA, 113 pp, doi: 10.5065/ D68S4MVH. [Link]

Stanski, H. R., L. J. Wilson, and W. R. Burrows, 1989: Survey of common verification methods in meteorology. WMO World Weather Watch Technical Report No. 8, WMO/TD No. 358, Geneva, 18-28.

Stull, R. B., 1988: An Introduction to Boundary Layer Meteorology, Atmospheric Sciences Library, Vol. 13, Springer Netherlands, doi: 10.1007/978-94-009-3027-8. [Link]

Stull, R. B., 1991: Static stability-An update. Bull. Amer. Meteorol. Soc., 72, 1521-1529, doi: 10.1175/15200477(1991)072<1521:SSU>2.0.CO;2. [Link]

Sukoriansky, S., 2008: Implementation of the Quasi-Normal Scale Elimination (QNSE) model of stably stratified turbulence in WRF. Report on WRF-DTC Visit of Semion Sukoriansky, June 2008.

Sukoriansky, S., B. Galperin, and V. Perov, 2005: Application of a new spectral theory of stably stratified turbulence to the atmospheric boundary layer over sea ice. Bound.-Layer Meteor., 117, 231-257, doi: 10.1007/ s10546-004-6848-4. [Link]

Sun, W. Y. and Y. Ogura, 1980: Modeling the evolution of the convective planetary boundary layer. $J$. Atmos. Sci., 37, 1558-1572, doi: 10.1175/1520-0469(1980)037<1558:MTEOTC>2.0.CO;2. [Link]

Tong, M. and M. Xue, 2008a: Simultaneous estimation of microphysical parameters and atmospheric 
state with simulated radar data and ensemble square root Kalman filter. Part II: Parameter estimation experiments. Mon Weather Rev, 136, 1649-1668, doi: 10.1175/2007MWR2071.1. [Link]

Tong, M. and M. Xue, 2008b: Simultaneous estimation of microphysical parameters and atmospheric state with simulated radar data and ensemble square root Kalman filter. Part I: Sensitivity analysis and parameter identifiability. Mon Weather Rev, 136, 1630-1648, doi: 10.1175/2007MWR2070.1. [Link]

Wang, D. and T. Zhang, 1989: The band characteristics of long-term variation of precipitation and water resources in East Asia monsoon region. Adv. Atmos. Sci., 6, 347-356, doi: 10.1007/BF02661540. [Link]

Wang, S., E. Yu, and H. Wang, 2012: A simulation study of a heavy rainfall process over the Yangtze River valley using the two-way nesting approach. Adv. Atmos. Sci., 29, 731-743, doi: 10.1007/s00376-012-1176-y. [Link]

Xu, G., M. Li, and Z. Zhang, 1985: Seasonal variation of rain-belts over China. Adv. Atmos. Sci., 2, 368-375, doi: 10.1007/BF02677253. [Link]

Xu, H., Y. Zhu, R. Liu, H. Shen, D. Wang, and G. Zhai, 2013: Simulation experiments with different planetary boundary layer schemes in the lower reaches of the Yangtze River. Chin. J. Atmos. Sci., 37, 149-159, doi: 10.3878/j.issn.1006-9895.2012.12021. (in Chinese) [Link]

Xu, L. and M. Zhao, 2000: The influences of boundary layer parameterization schemes on mesoscale heavy rain system. Adv. Atmos. Sci., 17, 458-472, doi: 10.1007/ s00376-000-0036-3. [Link]

Yihui, D. and W. Zunya, 2008: A study of rainy seasons in China. Meteorol. Atmos. Phys., 100, 121-138, doi: 10.1007/s00703-008-0299-2. [Link]

Zhai, P., X. Zhang, H. Wan, and X. Pan, 2005: Trends in total precipitation and frequency of daily precipitation extremes over China. J. Climate, 18, 1096-1108, doi: 10.1175/JCLI-3318.1. [Link] 